\title{
Concerns Involving the Self: What Is It That You Really Worry about, Regret, or Are Anxious about, When Things Do Not Go Right for You?
}

\author{
Kohji Hayase \\ Graduate School of Integrated Arts and Sciences, Hiroshima University, Higashihiroshima, Hiroshima, Japan \\ Email: hayasekoj@hiroshima-u.ac.jp
}

Received 15 March 2016; accepted 25 April 2016; published 28 April 2016

Copyright (C) 2016 by author and Scientific Research Publishing Inc.

This work is licensed under the Creative Commons Attribution International License (CC BY).

http://creativecommons.org/licenses/by/4.0/

(c) (i) Open Access

\begin{abstract}
In two studies conducted in the US and Japan in 2012, more than 1000 respondents in each country were asked to report their subjective opinions and attitudes about situations that caused them regret, concern, worry, and anxiety. Although exploratory factor analyses extracted many latent factors from the $\mathbf{8 0}$ questions, a common latent inner factor was extracted from five questions that examined key psychological phenomena: worry at the present time, bothersome concerns in the present, regret for the past, anxiety about the future, and unpleasant experience in the past. Confirmatory factor analyses and structural equation modeling of the latent variables (SEM/LV) provided convincing evidence of the existence of the common latent inner factor in both countries. Because each of the five key phenomena reflected concerns involving the self, the common latent inner factor was labeled "Being unable to detach from concerns involving the self." The same latent inner factor was also confirmed in SEM/LV of the combined USJapanese data. Women, younger people, and people with lower levels of education were less able to detach from concerns involving the self than were men, older people, and people with higher levels of education. This was true in the samples from both independent (US) and interdependent (Japan) cultures. Psychological and philosophical implications of the latent inner factor were discussed.
\end{abstract}

\section{Keywords}

Inability to Detach, Concerns Involving the Self, Worry, Regret, Anxiety, Happiness 


\section{Introduction}

Until recently, little research has examined mental constructs of happiness by means of introspective investigation (Raibley, 2012). Although happiness is often thought of as being identical to satisfaction (e.g. Diener et al., 1985; Diener et al., 1985; Schimmack \& Oishi, 2005; Oishi \& Sullivan, 2006; Nickerson et al., 2007; Xiao \& Li, 2011), satisfaction is merely one aspect of happiness. Consider a questionnaire that asks, "Will you be satisfied with your future life?" It is difficult to imagine anyone responding, "Yes, I will surely be satisfied with my future life,” because every person often confronts occasions when things do not turn out satisfactorily. Therefore, it is difficult to evaluate happiness only in terms of satisfaction.

What do you do when things do not turn out satisfactorily? At the time, you may try to change the situation. If you can change the situation so as to produce a satisfactory outcome, you will be satisfied, and you will experience a kind of happiness, sometimes known as episodic happiness (Raibley, 2012). However, if you cannot change the situation so as to produce a satisfactory outcome, what do you do? If you still believe that things should immediately and certainly turn out well for you, you may try again to alter the situation by other methods. But after repeated failures, you realize that the situation cannot be changed any more. Such occasions occur every second of every day. What do you do on the occasions when things certainly not to go right for you?

This is a difficult problem, and it is important to study, investigate, and solve it in order to discover and clarify the circumstances of real happiness, not merely episodic happiness (Raibley, 2012). In order to investigate this, an Internet survey about people's mental constructs related to happiness was carried out in the US and Japan. The questionnaire included eighty psychological and/or philosophical questions and four demographic questions about gender, age, education, and income. Psychological latent factors were extracted from the eighty questions in an exploratory analysis. Confirmatory factor analyses were carried out that included these attributes. Among the many psychological inner latent factors, this study reports and discusses a significant factor related to the above theme: "What did you do when things certainly did not turn out right for you?"

Even when things certainly do not turn out satisfactorily for you, you may often still have strong concerns (thoughts and/or desires) involving yourself, and simultaneously you may become irritated (Weber et al., 2007), worried (Freeston et al., 1994; Bergman et al., 2000; Brosschot, 2006; Sugiura, 2007; McEvoy et al., 2010; Stokes \& Hirsch, 2010), anxious (Zinbarg, 1998; Carleton et al., 2007; Hoffman et al., 2008; Carleton et al., 2012), or regretful (Saffrey et al., 2008; Komiya et al., 2012; Roese et al., 2009), and you may negatively ruminate (Nolen-Hoeksema et al., 2008; Taku, 2009) and/or engage in repetitive negative thinking (Ehring \& Watkins, 2008; Ehring et al., 2011) about your concerns. It may be possible that you experience a kind of unhappiness on this occasion (as a consequence of becoming irritated, worried, anxious, or regretful, or negatively ruminating and/or engaging in repetitive negative thinking). However, little research has investigated the inner latent factors or objects about which you worry, are anxious or regretful, and/or negatively ruminate, when things certainly did not go right for you. While "uncertainty" is sometimes regarded as a target or an object about which you worry or are anxious (Carleton et al., 2007; Carleton et al., 2012), "uncertainty” is not an inner introspective phenomenon.

The purpose of the present study is to make it possible to identify the true inner target or object about which you worry, are anxious or regretful, and/or negatively ruminate when things do not go right for you.

\section{Study 1 (US, 2012)}

\subsection{Method}

\subsubsection{Respondents}

It is well known that many substantial cultural variations exist between independent (e.g., Euro-American) and interdependent (e.g., Asian) cultures (Uchida et al., 2004; Uchida et al., 2008; Uchida et al., 2009). The US population comprises many different ethnicities of both independent and interdependent cultural origins (White, Hispanic, Black, Asian, Pacific Islander, etc.), and these differences may affect survey results. Therefore a single US ethnicity, White, was selected to represent an independent cultural origin and to contrast effectively with a Japanese sample, representing an interdependent culture. A total of 1125 US respondents who selected "White" as their ethnicity (540 men and 585 women; average age 44.7 years, standard deviation 14.1) participated.

Respondents were registered with a social survey company, Survey Sampling International, which has over one million respondents from all over the United States. The total column of Table 1 shows the age distribution of the respondents. Each year within each age decade was represented by a number of respondents (e.g., for 
women, 9 20-year-olds, 8 21-year olds, 13 22-year-olds, 8 23-year-olds, and so on). There was no correlation between gender and age, and the demographic distribution of the respondents was statistically ideal for the study of correlations of factors with gender and age.

\subsubsection{Measurement of Variables}

The questionnaire included a brief demographic survey asking gender Q1 and age Q2. Respondents selected one of the following options to indicate their individual annual income Q3: (1) Less than 10 thousand USD (US dollars), (2) Between 10 and 20 thousand USD, (3) Between 20 and 30 thousand USD, (4)... (9), (10) Between 90 and 100 thousand USD, (11)... (13), (14) Between 200 and 400 thousand USD, (15) 400 thousand USD or more, (16) Don’t know/Prefer not to answer.

Respondents selected one of the following options to indicate their level of education Q4: (1) Graduated from primary school, (2) Graduated from junior high school, (3) Graduated from high school or vocational school, (4) Graduated from specialized vocational school or junior college, (5) Graduated from university, (6) Graduated from graduate school. The questionnaire included a total of 80 questions (Q5L1 to Q12L10). A single latent inner factor was extracted from the following five critical questions:

Q5L5: "I am often not able to cut loose from worries even when things were certainly found not to go right for me.”

Q8L1: "I find it almost impossible to get my mind off concerns that are bothering me.”

Q8L4: "I often end up regretting something forever."

Q8L7: "I am not able to cut loose from uneasy occurrence and anxiety which may happen in the future.”

Q8L10:"I find it almost impossible to get my mind off an unpleasant experience once I have had it."

Respondents selected one of the following options to answer: strongly agree, agree, somewhat agree, somewhat disagree, disagree, and strongly disagree. The six alternatives were shown in the above order, and the items were not numbered. Respondents were asked to report their subjective opinions and/or attitudes toward the situation in the question.

\subsubsection{Procedures}

Participants were randomly selected from the subscribers of Survey Sampling International, and the questionnaires were sent to them via the Internet. The respondents completed the questionnaires at some time from the 6th to the 13th of January 2012. The respondents received compensation for participating in the survey. All respondents provided informed consent.

The sampling bias of respondents was small, as Survey Sampling International rigorously performs identity verification and maintenance after respondent registration. In the process of individual identity verification, Survey Sampling International sends a packet to the respondent's registered address to verify the individual's identity and location. Survey Sampling International prevents double respondent registration by checking duplicate email addresses. In performing maintenance after respondent registration, Survey Sampling International conducts quality surveys and checks the cookies stored on the respondents' computers.

\subsubsection{Statistical Analysis}

Path analysis (SEM: Structural Equation Modeling) was selected rather than multiple regression analysis for the following reasons. When analyzing three variables A, B and C, in which A predicts B and B predicts C, it is necessary to consider a model of chaining predictions, which admits different variables and permits an evaluation of model appropriateness by path analysis (SEM). However, such a model cannot be analyzed by means of multiple regression analysis, because in such an analysis, each A, B or C can be only an independent or a dependent variable. Moreover, the set for path analysis (SEM) completely includes the set for multiple regression analysis. Therefore, path analysis (SEM) was selected over multiple regression analysis.

\subsection{Results and Discussion}

\subsubsection{Confirmatory Factor Analyses by Structural Equation Modeling of the Latent Variables (SEM/LV)}

Exploratory and confirmatory factor analyses were used to demonstrate the statistical validity of latent factors obtained from the questionnaire.

While many psychological latent factors were extracted from the eighty questions of the questionnaire in the 
exploratory factor analysis, special attention was paid to a latent inner factor extracted from the five questions Q5L5, Q8L1, Q8L4, Q8L7, and Q8L10 (Cronbach's alpha 0.847), which represent rather different psychological phenomena:Q5L5 ("I am often not able to cut loose from worries even when things were certainly found not to go right for me") represents "worry" at the present time; Q8L1 ("I find it almost impossible to get my mind off concerns that are bothering me") reflects "bothersome concerns" in the present; Q8L4 ("I often end up regretting something forever") indicates "regret" for the past; Q8L7 ("I am not able to cut loose from uneasy occurrence and anxiety which may happen in the future") reflects "anxiety" about the future; and Q8L10 ("I find it almost impossible to get my mind off an unpleasant experience once I have had it") indicates "unpleasant experience" in the past. In order to demonstrate the statistical validity of the latent factor extracted from these different phenomena, a confirmatory factor analysis was carried out.

The confirmatory factor analysis of the latent factor and structural equation modeling of the latent variables (SEM/LV) were carried out using Amos19. Frequency distributions of responses to Q5L5, Q8L1, Q8L4, Q8L7, and Q8L10 of the US sample are represented in Tables 1-5 as cross tabulation scores by gender and age group. The analysis included the attributes of gender, age, level of education, and annual income, which predicted the latent factor, as illustrated in Figure 1. In this path analysis, the relationship with predictivity (not causality) was as follows. It was assumed that gender, age, level of education, and annual income would predict the latent factor in Figure 1. Gender and age are basic predictors that are not predicted by anything else, and it is reasonable to assume that gender and age might predict the level of education and annual income. On the other hand, the level of education may predict annual income, because the mean level of education is decided around or below twenty years of age, whereas mean annual income from an occupation is decided at a rather older age. Therefore level of education was assumed to predict annual income.

In Figure 1, only significant paths are drawn $(p<0.05)$, the latent factor is a latent variable, unnamed at present, and attributes are the observed variables as predictors. Goodness of fit for SEM/LV was acceptable: RMSEA was 0.057 (RMSEA $\leq 0.06$ or less; Hu \& Bentler, 1999), CFI was 0.970, and factor loadings were 0.657 for Q5L5 ( $p<0.001), 0.770$ for Q8L1 ( $p<0.001), 0.649$ for Q8L4 $(p<0.001), 0.738$ for Q8L7 $(p<0.001)$, and 0.814 for Q8L10 $(p<0.001)$. The model fit was good, because direct paths connected nearly all variables. We

Table 1. Cross tabulation scores by gender and age group. Frequency distributions of responses to Q5L5 of US White in 2012. Number of respondents that selected the response (numbers in parentheses are its percentage).

\begin{tabular}{|c|c|c|c|c|c|c|c|c|c|c|c|c|c|c|c|}
\hline \multirow{2}{*}{$\begin{array}{l}\text { Age } \\
20 \mathrm{~s}\end{array}$} & \multirow{2}{*}{$\begin{array}{c}\text { Gender } \\
\text { Men }\end{array}$} & \multicolumn{2}{|c|}{$\begin{array}{l}\text { Strongly } \\
\text { agree }\end{array}$} & \multicolumn{2}{|c|}{ Agree } & \multicolumn{2}{|c|}{$\begin{array}{l}\text { Somewhat } \\
\text { agree }\end{array}$} & \multicolumn{2}{|c|}{$\begin{array}{l}\text { Somewhat } \\
\text { disagree }\end{array}$} & \multicolumn{2}{|c|}{ Disagree } & \multicolumn{2}{|c|}{$\begin{array}{l}\text { Strongly } \\
\text { disagree }\end{array}$} & \multicolumn{2}{|c|}{ Total } \\
\hline & & 13 & (12.9) & 24 & (23.8) & 29 & (28.7) & 15 & (14.9) & 18 & (17.8) & 2 & (2.0) & 101 & (100.0) \\
\hline & Women & 13 & (11.5) & 30 & (26.5) & 28 & (24.8) & 22 & (19.5) & 14 & (12.4) & 6 & (5.3) & 113 & (100.0) \\
\hline & Both & 26 & (12.1) & 54 & (25.2) & 57 & (26.6) & 37 & (17.3) & 32 & (15.0) & 8 & (3.7) & 214 & (100.0) \\
\hline \multirow[t]{3}{*}{$30 \mathrm{~s}$} & Men & 13 & $(12.0)$ & 25 & (23.1) & 28 & (25.9) & 16 & (14.8) & 16 & (14.8) & 10 & (9.3) & 108 & (100.0) \\
\hline & Women & 12 & $(10.4)$ & 27 & (23.5) & 35 & (30.4) & 24 & (20.9) & 15 & (13.0) & 2 & (1.7) & 115 & (100.0) \\
\hline & Both & 25 & (11.2) & 52 & (23.3) & 63 & (28.3) & 40 & (17.9) & 31 & (13.9) & 12 & (5.4) & 223 & $(100.0)$ \\
\hline \multirow[t]{3}{*}{$40 \mathrm{~s}$} & Men & 12 & (11.0) & 25 & (22.9) & 29 & (26.6) & 19 & (17.4) & 15 & (13.8) & 9 & (8.3) & 109 & $(100.0)$ \\
\hline & Women & 20 & (17.5) & 28 & (24.6) & 30 & (26.3) & 22 & (19.3) & 11 & (9.6) & 3 & (2.6) & 114 & $(100.0)$ \\
\hline & Both & 32 & (14.3) & 53 & (23.8) & 59 & (26.5) & 41 & (18.4) & 26 & (11.7) & 12 & (5.4) & 223 & (100.0) \\
\hline \multirow[t]{3}{*}{$50 \mathrm{~s}$} & Men & 10 & (8.8) & 27 & (23.9) & 31 & (27.4) & 21 & (18.6) & 19 & (16.8) & 5 & $(4.4)$ & 113 & $(100.0)$ \\
\hline & Women & 29 & (23.8) & 25 & (20.5) & 27 & (22.1) & 18 & (14.8) & 16 & (13.1) & 7 & (5.7) & 122 & $(100.0)$ \\
\hline & Both & 39 & (16.6) & 52 & (22.1) & 58 & (24.7) & 39 & (16.6) & 35 & (14.9) & 12 & (5.1) & 235 & (100.0) \\
\hline \multirow[t]{3}{*}{$60 \mathrm{~s}$} & Men & 7 & (6.4) & 20 & (18.3) & 32 & (29.4) & 25 & (22.9) & 16 & $(14.7)$ & 9 & (8.3) & 109 & $(100.0)$ \\
\hline & Women & 9 & (7.4) & 28 & (23.1) & 29 & $(24.0)$ & 26 & (21.5) & 19 & (15.7) & 10 & (8.3) & 121 & (100.0) \\
\hline & Both & 16 & (7.0) & 48 & (20.9) & 61 & (26.5) & 51 & $(22.2)$ & 35 & $(15.2)$ & 19 & (8.3) & 230 & $(100.0)$ \\
\hline \multirow[t]{3}{*}{ Total } & Men & 55 & (10.2) & 121 & (22.4) & 149 & (27.6) & 96 & (17.8) & 84 & (15.6) & 35 & (6.5) & 540 & (100.0) \\
\hline & Women & 83 & (14.2) & 138 & (23.6) & 149 & (25.5) & 112 & (19.1) & 75 & (12.8) & 28 & (4.8) & 585 & (100.0) \\
\hline & Both & 138 & (12.3) & 259 & (23.0) & 298 & (26.5) & 208 & (18.5) & 159 & (14.1) & 63 & (5.6) & 1125 & (100.0) \\
\hline
\end{tabular}


Table 2. Cross tabulation scores by gender and age group. Frequency distributions of responses to Q8L1 of US White in 2012. Number of respondents that selected the response (numbers in parentheses are its percentage).

\begin{tabular}{|c|c|c|c|c|c|c|c|c|c|c|c|c|c|c|c|}
\hline \multirow{2}{*}{$\begin{array}{l}\text { Age } \\
\text { 20s }\end{array}$} & \multirow{2}{*}{$\begin{array}{c}\text { Gender } \\
\text { Men }\end{array}$} & \multicolumn{2}{|c|}{$\begin{array}{l}\text { Strongly } \\
\text { agree }\end{array}$} & \multicolumn{2}{|c|}{ Agree } & \multicolumn{2}{|c|}{$\begin{array}{l}\text { Somewhat } \\
\text { agree }\end{array}$} & \multicolumn{2}{|c|}{$\begin{array}{c}\text { Somewhat } \\
\text { disagree }\end{array}$} & \multicolumn{2}{|c|}{ Disagree } & \multicolumn{2}{|c|}{$\begin{array}{l}\text { Strongly } \\
\text { disagree }\end{array}$} & \multicolumn{2}{|c|}{ Total } \\
\hline & & 22 & (21.8) & 27 & (26.7) & 30 & (29.7) & 16 & (15.8) & 6 & (5.9) & 0 & 0.0 & 101 & (100) \\
\hline & Women & 22 & (19.5) & 39 & (34.5) & 24 & (21.2) & 15 & (13.3) & 9 & (8.0) & 4 & (3.5) & 113 & (100) \\
\hline & Both & 44 & (20.6) & 66 & (30.8) & 54 & (25.2) & 31 & (14.5) & 15 & (7.0) & 4 & (1.9) & 214 & (100) \\
\hline \multirow[t]{3}{*}{$30 \mathrm{~s}$} & Men & 19 & $(17.6)$ & 30 & $(27.8)$ & 22 & (20.4) & 16 & (14.8) & 16 & (14.8) & 5 & $(4.6)$ & 108 & (100) \\
\hline & Women & 18 & (15.7) & 28 & (24.3) & 37 & $(32.2)$ & 20 & (17.4) & 9 & (7.8) & 3 & (2.6) & 115 & (100) \\
\hline & Both & 37 & (16.6) & 58 & $(26.0)$ & 59 & (26.5) & 36 & (16.1) & 25 & $(11.2)$ & 8 & (3.6) & 223 & (100) \\
\hline \multirow[t]{3}{*}{$40 \mathrm{~s}$} & Men & 13 & (11.9) & 21 & (19.3) & 41 & (37.6) & 18 & (16.5) & 11 & (10.1) & 5 & (4.6) & 109 & (100) \\
\hline & Women & 26 & (22.8) & 35 & $(30.7)$ & 33 & (28.9) & 13 & (11.4) & 6 & (5.3) & 1 & $(0.9)$ & 114 & (100) \\
\hline & Both & 39 & (17.5) & 56 & (25.1) & 74 & (33.2) & 31 & (13.9) & 17 & (7.6) & 6 & (2.7) & 223 & (100) \\
\hline \multirow[t]{3}{*}{$50 \mathrm{~s}$} & Men & 14 & (12.4) & 28 & (24.8) & 31 & $(27.4)$ & 17 & $(15.0)$ & 19 & (16.8) & 4 & (3.5) & 113 & (100) \\
\hline & Women & 22 & (18.0) & 32 & $(26.2)$ & 37 & (30.3) & 18 & (14.8) & 9 & (7.4) & 4 & (3.3) & 122 & (100) \\
\hline & Both & 36 & (15.3) & 60 & (25.5) & 68 & (28.9) & 35 & (14.9) & 28 & (11.9) & 8 & (3.4) & 235 & (100) \\
\hline \multirow[t]{3}{*}{$60 \mathrm{~s}$} & Men & 9 & (8.3) & 19 & (17.4) & 39 & (35.8) & 26 & (23.9) & 16 & (14.7) & 0 & 0.0 & 109 & (100) \\
\hline & Women & 16 & (13.2) & 25 & (20.7) & 41 & (33.9) & 27 & (22.3) & 9 & (7.4) & 3 & (2.5) & 121 & (100) \\
\hline & Both & 25 & (10.9) & 44 & (19.1) & 80 & (34.8) & 53 & $(23.0)$ & 25 & (10.9) & 3 & (1.3) & 230 & (100) \\
\hline \multirow[t]{3}{*}{ Total } & Men & 77 & (14.3) & 125 & (23.1) & 163 & $(30.2)$ & 93 & $(17.2)$ & 68 & (12.6) & 14 & (2.6) & 540 & (100) \\
\hline & Women & 104 & $(17.8)$ & 159 & $(27.2)$ & 172 & (29.4) & 93 & (15.9) & 42 & (7.2) & 15 & (2.6) & 585 & (100) \\
\hline & Both & 181 & (16.1) & 284 & (25.2) & 335 & (29.8) & 186 & (16.5) & 110 & (9.8) & 29 & (2.6) & 1125 & (100) \\
\hline
\end{tabular}

Table 3. Cross tabulation scores by gender and age group. Frequency distributions of responses to Q8L4 of US White in 2012. Number of respondents that selected the response (numbers in parentheses are its percentage).

\begin{tabular}{|c|c|c|c|c|c|c|c|c|c|c|c|c|c|c|c|}
\hline \multirow{2}{*}{$\begin{array}{l}\text { Age } \\
\text { 20s }\end{array}$} & \multirow{2}{*}{$\begin{array}{c}\text { Gender } \\
\text { Men }\end{array}$} & \multicolumn{2}{|c|}{$\begin{array}{l}\text { Strongly } \\
\text { agree }\end{array}$} & \multicolumn{2}{|c|}{ Agree } & \multicolumn{2}{|c|}{$\begin{array}{c}\text { Somewhat } \\
\text { agree }\end{array}$} & \multicolumn{2}{|c|}{$\begin{array}{c}\text { Somewhat } \\
\text { disagree }\end{array}$} & \multicolumn{2}{|c|}{ Disagree } & \multicolumn{2}{|c|}{$\begin{array}{l}\text { Strongly } \\
\text { disagree }\end{array}$} & \multicolumn{2}{|c|}{ Total } \\
\hline & & 12 & (11.9) & 13 & (12.9) & 26 & (25.7) & 20 & (19.8) & 21 & (20.8) & 9 & (8.9) & 101 & (100) \\
\hline & Women & 7 & (6.2) & 12 & (10.6) & 24 & $(21.2)$ & 25 & (22.1) & 25 & (22.1) & 20 & (17.7) & 113 & (100) \\
\hline & Both & 19 & (8.9) & 25 & (11.7) & 50 & (23.4) & 45 & (21.0) & 46 & (21.5) & 29 & (13.6) & 214 & (100) \\
\hline \multirow[t]{3}{*}{$30 \mathrm{~s}$} & Men & 9 & (8.3) & 12 & (11.1) & 27 & (25.0) & 22 & (20.4) & 22 & (20.4) & 16 & (14.8) & 108 & $(100)$ \\
\hline & Women & 6 & (5.2) & 12 & (10.4) & 25 & (21.7) & 39 & (33.9) & 23 & (20.0) & 10 & (8.7) & 115 & (100) \\
\hline & Both & 15 & $(6.7)$ & 24 & (10.8) & 52 & (23.3) & 61 & $(27.4)$ & 45 & (20.2) & 26 & (11.7) & 223 & $(100)$ \\
\hline \multirow[t]{3}{*}{$40 \mathrm{~s}$} & Men & 8 & (7.3) & 11 & (10.1) & 25 & (22.9) & 38 & (34.9) & 13 & (11.9) & 14 & (12.8) & 109 & $(100)$ \\
\hline & Women & 7 & (6.1) & 17 & (14.9) & 27 & (23.7) & 36 & (31.6) & 22 & (19.3) & 5 & $(4.4)$ & 114 & (100) \\
\hline & Both & 15 & $(6.7)$ & 28 & (12.6) & 52 & (23.3) & 74 & (33.2) & 35 & (15.7) & 19 & (8.5) & 223 & (100) \\
\hline \multirow[t]{3}{*}{$50 \mathrm{~s}$} & Men & 6 & (5.3) & 9 & $(8.0)$ & 29 & (25.7) & 23 & $(20.4)$ & 33 & $(29.2)$ & 13 & (11.5) & 113 & (100) \\
\hline & Women & 5 & $(4.1)$ & 12 & (9.8) & 29 & (23.8) & 39 & (32.0) & 22 & (18.0) & 15 & (12.3) & 122 & (100) \\
\hline & Both & 11 & $(4.7)$ & 21 & (8.9) & 58 & (24.7) & 62 & (26.4) & 55 & (23.4) & 28 & (11.9) & 235 & $(100)$ \\
\hline \multirow[t]{4}{*}{$60 \mathrm{~s}$} & Men & 3 & $(2.8)$ & 11 & (10.1) & 20 & (18.3) & 35 & (32.1) & 28 & (25.7) & 12 & (11.0) & 109 & $(100)$ \\
\hline & Women & 3 & $(2.5)$ & 9 & $(7.4)$ & 26 & (21.5) & 39 & (32.2) & 32 & (26.4) & 12 & (9.9) & 121 & $(100)$ \\
\hline & Both & 6 & (2.6) & 20 & (8.7) & 46 & (20.0) & 74 & (32.2) & 60 & (26.1) & 24 & (10.4) & 230 & (100) \\
\hline & Men & 38 & $(7.0)$ & 56 & $(10.4)$ & 127 & (23.5) & 138 & (25.6) & 117 & (21.7) & 64 & (11.9) & 540 & (100) \\
\hline \multirow[t]{2}{*}{ Total } & Women & 28 & (4.8) & 62 & (10.6) & 131 & (22.4) & 178 & (30.4) & 124 & $(21.2)$ & 62 & (10.6) & 585 & $(100)$ \\
\hline & Both & 66 & (5.9) & 118 & (10.5) & 258 & (22.9) & 316 & (28.1) & 241 & (21.4) & 126 & (11.2) & 1125 & $(100)$ \\
\hline
\end{tabular}


Table 4. Cross tabulation scores by gender and age group. Frequency distributions of responses to Q8L7 of US White in 2012. Number of respondents that selected the response (numbers in parentheses are its percentage).

\begin{tabular}{|c|c|c|c|c|c|c|c|c|c|c|c|c|c|c|c|}
\hline \multirow{2}{*}{$\begin{array}{l}\text { Age } \\
20 \mathrm{~s}\end{array}$} & \multirow{2}{*}{$\begin{array}{c}\text { Gender } \\
\text { Men }\end{array}$} & \multicolumn{2}{|c|}{$\begin{array}{l}\text { Strongly } \\
\text { agree }\end{array}$} & \multicolumn{2}{|c|}{ Agree } & \multicolumn{2}{|c|}{$\begin{array}{l}\text { Somewhat } \\
\text { agree }\end{array}$} & \multicolumn{2}{|c|}{$\begin{array}{c}\text { Somewhat } \\
\text { disagree }\end{array}$} & \multicolumn{2}{|c|}{ Disagree } & \multicolumn{2}{|c|}{$\begin{array}{l}\text { Strongly } \\
\text { disagree }\end{array}$} & \multicolumn{2}{|c|}{ Total } \\
\hline & & 8 & (7.9) & 23 & (22.8) & 28 & (27.7) & 24 & (23.8) & 16 & (15.8) & 2 & $(2.0)$ & 101 & (100) \\
\hline & Women & 6 & (5.3) & 27 & (23.9) & 25 & (22.1) & 31 & (27.4) & 19 & (16.8) & 5 & (4.4) & 113 & (100) \\
\hline & Both & 14 & (6.5) & 50 & $(23.4)$ & 53 & (24.8) & 55 & (25.7) & 35 & $(16.4)$ & 7 & (3.3) & 214 & (100) \\
\hline \multirow[t]{3}{*}{$30 \mathrm{~s}$} & Men & 10 & (9.3) & 15 & (13.9) & 30 & (27.8) & 28 & (25.9) & 17 & (15.7) & 8 & (7.4) & 108 & (100) \\
\hline & Women & 11 & (9.6) & 22 & (19.1) & 34 & (29.6) & 29 & $(25.2)$ & 14 & $(12.2)$ & 5 & (4.3) & 115 & (100) \\
\hline & Both & 21 & (9.4) & 37 & (16.6) & 64 & (28.7) & 57 & (25.6) & 31 & (13.9) & 13 & (5.8) & 223 & (100) \\
\hline \multirow[t]{3}{*}{$40 \mathrm{~s}$} & Men & 5 & $(4.6)$ & 11 & (10.1) & 36 & (33.0) & 26 & (23.9) & 19 & $(17.4)$ & 12 & $(11.0)$ & 109 & (100) \\
\hline & Women & 8 & (7.0) & 27 & (23.7) & 39 & $(34.2)$ & 24 & (21.1) & 13 & (11.4) & 3 & (2.6) & 114 & (100) \\
\hline & Both & 13 & (5.8) & 38 & $(17.0)$ & 75 & (33.6) & 50 & (22.4) & 32 & (14.3) & 15 & (6.7) & 223 & (100) \\
\hline \multirow[t]{3}{*}{$50 \mathrm{~s}$} & Men & 3 & (2.7) & 9 & $(8.0)$ & 34 & (30.1) & 32 & (28.3) & 24 & $(21.2)$ & 11 & (9.7) & 113 & (100) \\
\hline & Women & 13 & (10.7) & 18 & (14.8) & 34 & (27.9) & 28 & $(23.0)$ & 20 & (16.4) & 9 & (7.4) & 122 & (100) \\
\hline & Both & 16 & (6.8) & 27 & (11.5) & 68 & (28.9) & 60 & (25.5) & 44 & (18.7) & 20 & (8.5) & 235 & (100) \\
\hline \multirow[t]{3}{*}{$60 \mathrm{~s}$} & Men & 3 & (2.8) & 7 & (6.4) & 29 & (26.6) & 34 & (31.2) & 30 & (27.5) & 6 & (5.5) & 109 & (100) \\
\hline & Women & 6 & (5.0) & 11 & (9.1) & 32 & (26.4) & 30 & $(24.8)$ & 28 & $(23.1)$ & 14 & (11.6) & 121 & (100) \\
\hline & Both & 9 & (3.9) & 18 & (7.8) & 61 & (26.5) & 64 & $(27.8)$ & 58 & $(25.2)$ & 20 & (8.7) & 230 & (100) \\
\hline \multirow[t]{3}{*}{ Total } & Men & 29 & (5.4) & 65 & (12.0) & 157 & (29.1) & 144 & (26.7) & 106 & (19.6) & 39 & (7.2) & 540 & (100) \\
\hline & Women & 44 & (7.5) & 105 & (17.9) & 164 & (28.0) & 142 & (24.3) & 94 & (16.1) & 36 & (6.2) & 585 & (100) \\
\hline & Both & 73 & (6.5) & 170 & (15.1) & 321 & (28.5) & 286 & (25.4) & 200 & (17.8) & 75 & (6.7) & 1125 & (100) \\
\hline
\end{tabular}

Table 5. Cross tabulation scores by gender and age group. Frequency distributions of responses to Q8L10 of US White in 2012. Number of respondents that selected the response (numbers in parentheses are its percentage).

\begin{tabular}{|c|c|c|c|c|c|c|c|c|c|c|c|c|c|c|}
\hline \multirow{2}{*}{$\begin{array}{l}\text { Age } \\
20 s\end{array}$} & \multirow{2}{*}{$\begin{array}{c}\text { Gender } \\
\text { Men }\end{array}$} & \multicolumn{2}{|c|}{$\begin{array}{l}\text { Strongly } \\
\text { agree }\end{array}$} & \multicolumn{2}{|c|}{ Agree } & \multicolumn{2}{|c|}{$\begin{array}{l}\text { Somewhat } \\
\text { agree }\end{array}$} & \multicolumn{2}{|c|}{$\begin{array}{c}\text { Somewhat } \\
\text { disagree }\end{array}$} & \multicolumn{2}{|c|}{ Disagree } & \multicolumn{2}{|c|}{$\begin{array}{l}\text { Strongly } \\
\text { disagree }\end{array}$} & \multirow{2}{*}{$\begin{array}{c}\text { Total } \\
101\end{array}$} \\
\hline & & 14 & (13.9) & 21 & (20.8) & 32 & (31.7) & 20 & (19.8) & 13 & (12.9) & 1 & $(1.0)$ & \\
\hline & Women & 12 & $(10.6)$ & 25 & (22.1) & 26 & (23.0) & 27 & (23.9) & 16 & $(14.2)$ & 7 & $(6.2)$ & 113 \\
\hline & Both & 26 & (12.1) & 46 & (21.5) & 58 & (27.1) & 47 & $(22.0)$ & 29 & (13.6) & 8 & (3.7) & 214 \\
\hline \multirow[t]{3}{*}{$30 \mathrm{~s}$} & Men & 10 & (9.3) & 15 & (13.9) & 27 & (25.0) & 25 & (23.1) & 22 & $(20.4)$ & 9 & (8.3) & 108 \\
\hline & Women & 9 & (7.8) & 20 & (17.4) & 39 & (33.9) & 32 & (27.8) & 12 & (10.4) & 3 & (2.6) & 115 \\
\hline & Both & 19 & (8.5) & 35 & (15.7) & 66 & (29.6) & 57 & (25.6) & 34 & (15.2) & 12 & (5.4) & 223 \\
\hline \multirow[t]{3}{*}{$40 \mathrm{~s}$} & Men & 7 & (6.4) & 16 & (14.7) & 33 & (30.3) & 32 & (29.4) & 12 & $(11.0)$ & 9 & (8.3) & 109 \\
\hline & Women & 13 & (11.4) & 23 & (20.2) & 39 & (34.2) & 22 & (19.3) & 16 & $(14.0)$ & 1 & $(0.9)$ & 114 \\
\hline & Both & 20 & $(9.0)$ & 39 & (17.5) & 72 & (32.3) & 54 & $(24.2)$ & 28 & (12.6) & 10 & (4.5) & 223 \\
\hline \multirow[t]{3}{*}{$50 \mathrm{~s}$} & Men & 1 & (0.9) & 16 & (14.2) & 31 & (27.4) & 27 & (23.9) & 31 & (27.4) & 7 & (6.2) & 113 \\
\hline & Women & 9 & (7.4) & 25 & (20.5) & 33 & (27.0) & 29 & (23.8) & 22 & $(18.0)$ & 4 & (3.3) & 122 \\
\hline & Both & 10 & (4.3) & 41 & (17.4) & 64 & $(27.2)$ & 56 & (23.8) & 53 & (22.6) & 11 & (4.7) & 235 \\
\hline \multirow[t]{3}{*}{$60 \mathrm{~s}$} & Men & 9 & (8.3) & 11 & (10.1) & 23 & (21.1) & 34 & (31.2) & 23 & (21.1) & 9 & (8.3) & 109 \\
\hline & Women & 6 & (5.0) & 14 & (11.6) & 33 & (27.3) & 31 & (25.6) & 30 & $(24.8)$ & 7 & (5.8) & 121 \\
\hline & Both & 15 & (6.5) & 25 & (10.9) & 56 & (24.3) & 65 & (28.3) & 53 & (23.0) & 16 & $(7.0)$ & 230 \\
\hline \multirow[t]{3}{*}{ Total } & Men & 41 & (7.6) & 79 & (14.6) & 146 & $(27.0)$ & 138 & (25.6) & 101 & (18.7) & 35 & (6.5) & 540 \\
\hline & Women & 49 & (8.4) & 107 & (18.3) & 170 & (29.1) & 141 & (24.1) & 96 & (16.4) & 22 & (3.8) & 585 \\
\hline & Both & 90 & (8.0) & 186 & (16.5) & 316 & (28.1) & 279 & (24.8) & 197 & (17.5) & 57 & (5.1) & 1125 \\
\hline
\end{tabular}


specified the direction of scoring to make the nature of associations between the variables clearer. Table 6 provides more detailed information, including the matrix of correlations among all variables along with their means, SDs, correlation coefficients, and covariance. The significance tests for the paths are based on standardized coefficients. $\mathrm{R}^{2}$ was also added on a shoulder of each dependent variable in Figure 1.

Wang and Wang (2012) have noted the following limitations of the chi square statistic. First, because chisquare is defined as $\mathrm{N}-1$ times the fitting function, it is highly sensitive to sample size. With larger sample sizes, the probability of rejecting the model increases, resulting in Type I error (rejecting a correct hypothesis), even though differences between observed and model estimated variance/covariance matrices are trivial. Because this study used a considerably large sample of over 1000 participants, use of chi-square (as well as the related Cramer's V) was inappropriate.

Because each observational variable (Q5L5, Q8L1, Q8L4, Q8L7 and Q8L10) is equal to the true value + error, the sum of the errors is also represented in the weighted sum. Therefore, weighted sum errors do not decrease and may rather increase by addition, resulting in the well-known phenomena of "rarefication" or "thinning". It has often observed from data that the absolute values of correlation coefficients between observed variables are smaller than absolute values of correlation coefficients between latent factors. This is also regarded as a manifestation of rarefication or thinning, indicating that correlations between observed variables that are the sum of errors and true values are lower than correlations between true values that are latent factors without the addition of errors.

As a result, the absolute value of the correlation coefficient between the weighted sums should be lower than that of the correlation coefficient between latent variables obtained by factor analysis. On the other hand, the latent variable in SEM (path analysis) is expected to be rather closer to the true value than the weighted sum, if Cronbach's alpha is higher and the number of observational variables is larger. RMSEA (lower than 0.06) is useful (Hu \& Bentler, 1999) for evaluating the goodness of fit for modeling; therefore, SEM was adopted and

Table 6. Mean, standard deviation, correlation coefficient (Coef.) and covariance (Cova.) for Q1, Q2, Q4, Q3, Q5L5, Q8L1, Q8L4, Q8L7 and Q8L10 of US White in 2012.

\begin{tabular}{|c|c|c|c|c|c|c|c|c|c|c|}
\hline & & $\begin{array}{c}\text { Q1 } \\
\text { Gender }\end{array}$ & $\begin{array}{l}\text { Q2 } \\
\text { Age }\end{array}$ & $\begin{array}{l}\text { Q4 Level of } \\
\text { education }\end{array}$ & $\begin{array}{l}\text { Q3 Annual } \\
\text { income }\end{array}$ & Q5L5 & Q8L1 & Q8L4 & Q8L7 & Q8L10 \\
\hline \multicolumn{2}{|c|}{ Means } & 1.52 & 44.74 & 4.06 & 4.93 & 3.16 & 2.86 & 3.82 & 3.53 & 3.42 \\
\hline \multicolumn{2}{|c|}{ Standard devi. } & 0.500 & 14.111 & 1.107 & 3.127 & 1.397 & 1.291 & 1.345 & 1.303 & 1.308 \\
\hline \multirow{2}{*}{ Q1. Gender } & Coef. & 1.000 & -0.009 & -0.030 & -0.115 & -0.07 & -0.900 & 0.017 & -0.088 & -0.074 \\
\hline & Cova. & 0.250 & -0.064 & -0.017 & -0.181 & -0.05 & -0.058 & 0.011 & -0.057 & -0.049 \\
\hline \multirow{2}{*}{ Q2. Age } & Coef. & & 1.000 & $0.082^{* *}$ & $0.080^{* *}$ & $0.070^{*}$ & $0.105^{* *}$ & $0.066^{*}$ & $0.158^{* *}$ & $0.141^{* *}$ \\
\hline & Cova. & & 199.1 & 1.284 & 3.505 & 1.375 & 1.921 & 1.261 & 2.913 & 2.609 \\
\hline \multirow{2}{*}{$\begin{array}{l}\text { Q4. Level of } \\
\text { education }\end{array}$} & Coef. & & & 1.000 & $0.364^{* *}$ & $0.069^{*}$ & $0.101^{* *}$ & $0.079^{* *}$ & 0.011 & $0.072^{*}$ \\
\hline & Cova. & & & 1.225 & 1.257 & 0.107 & 0.144 & 0.117 & 0.017 & 0.104 \\
\hline \multirow{2}{*}{$\begin{array}{l}\text { Q3. Annual } \\
\text { income }\end{array}$} & Coef. & & & & 1.000 & 0.025 & $0.079^{*}$ & 0.009 & -0.007 & 0.038 \\
\hline & Cova. & & & & 9.777 & 0.107 & 0.316 & 0.037 & -0.027 & 0.155 \\
\hline \multirow{2}{*}{ Q5L5 } & Coef. & & & & & 1.000 & $0.541^{* *}$ & $0.386^{* *}$ & $0.529^{* *}$ & $0.497^{* *}$ \\
\hline & Cova. & & & & & 1.951 & 0.976 & 0.726 & 0.963 & 0.909 \\
\hline \multirow{2}{*}{ Q8L1 } & Coef. & & & & & & 1.000 & $0.471^{* *}$ & $0.560^{* *}$ & $0.629^{* *}$ \\
\hline & Cova. & & & & & & 1.667 & 0.818 & 0.942 & 1.063 \\
\hline \multirow{2}{*}{ Q8L4 } & Coef. & & & & & & & 1.000 & $0.473^{* *}$ & $0.580^{* *}$ \\
\hline & Cova. & & & & & & & 1.809 & 0.829 & 1.021 \\
\hline \multirow{2}{*}{ Q8L7 } & Coef. & & & & & & & & 1.000 & $0.588^{* *}$ \\
\hline & Cova. & & & & & & & & 1.698 & 1.003 \\
\hline \multirow{2}{*}{ Q8L10 } & Coef. & & & & & & & & & 1.000 \\
\hline & Cova. & & & & & & & & & 1.711 \\
\hline
\end{tabular}

\footnotetext{
${ }^{* *} p<0.01, \stackrel{*}{p}<0.05$.
} 


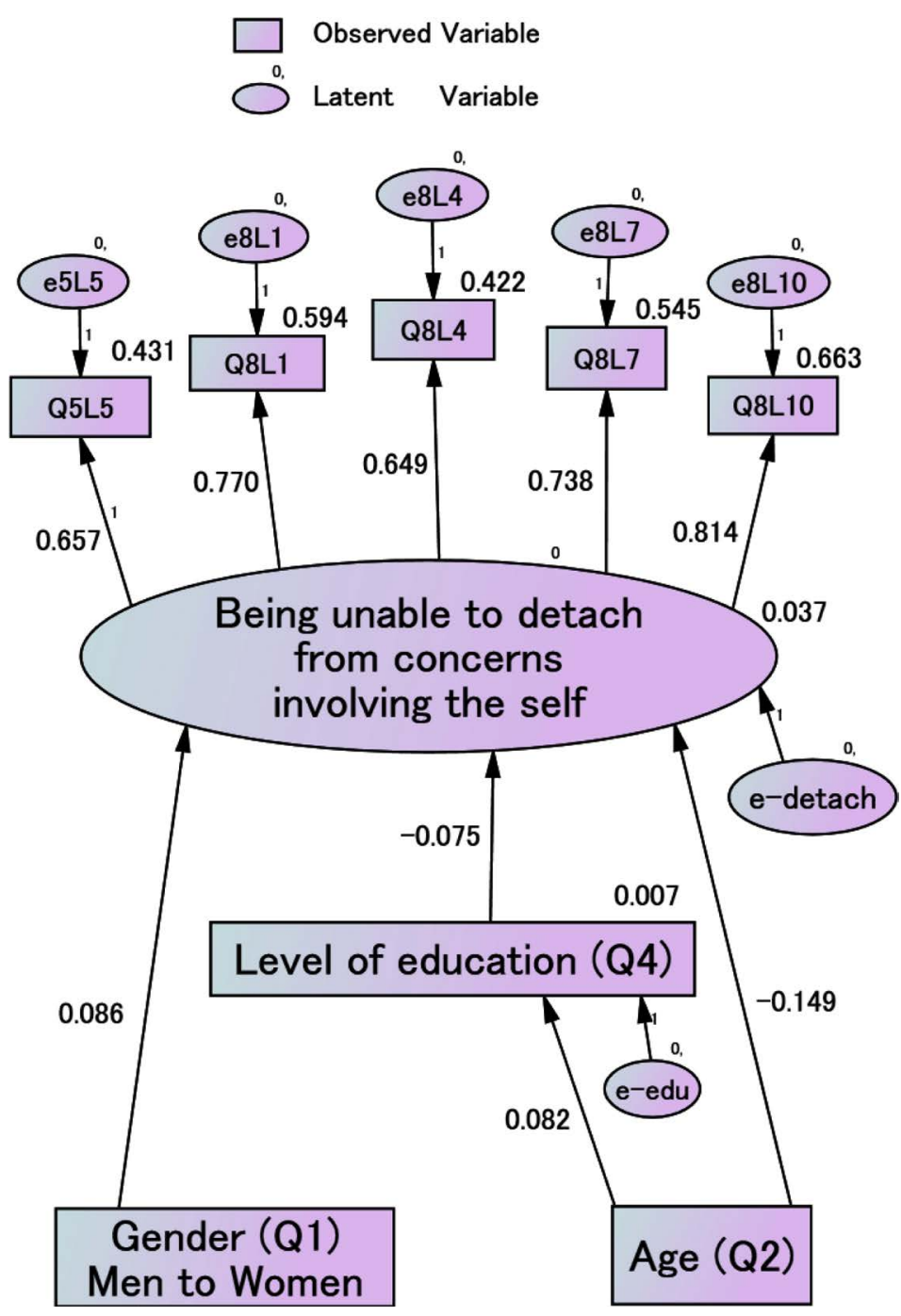

Figure 1. Confirmatory factor analysis of "Being unable to detach from concerns involving the self" and SEM/LV including the four attributes (gender, age, level of education and annual income) that predicted the factor, in the US sample. Correlation coefficients between "Being unable to detach from concerns involving the self" and the four attributes are written only for paths with $p<0.05$. The questions were as follows: [Q1]: Gender (Men to Women); [Q2]: Age; [Q3]: Annual income; [Q4]: Level of education, [Q5L5] indicated respondents' inability to cut loose from worries even when things were certainly found not to go right for them. [Q8L1] indicated respondents' inability to get their minds off concerns that are bothering them. [Q8L4] indicated that respondents' inability to not end up regretting something forever. [Q8L7] indicated respondents' inability to cut loose from uneasy occurrences and anxiety which may happen in the future. [Q8L10] indicated respondents' inability to get their minds off an unpleasant experience once they have had it. Factor loadings for [Q5L5], [Q8L1] [Q8L4] [Q8L7] and [Q8L10] (all $p<0.001$ ) are indicated along the paths. $\mathrm{R}^{2}$ is indicated on shoulder of each dependent variable.

more importance was attached to RMSEA.

A confirmatory factor analysis by SEM/LV clearly revealed that a common latent inner factor could be extracted from the five questions.

\subsubsection{What Is the Latent Inner Factor?}

The five phenomena, worry (Q5L5), bothersome concern (Q8L1), regret (Q8L4), anxiety (Q8L7), and unpleasant experience (Q8L10) are considered to be distinct psychological phenomena (Ehring \& Watkins, 2008; McEvoy et al., 2010). The time focus of the questions also differed: present (Q5L5, Q8L1), past (Q8L4, Q8L10), and future (Q8L7). Therefore, it may seem implausible that a common latent inner factor could be extracted from the five questions (Davey et al., 1992; Stober \& Joormann, 2001). On the other hand, Zebb (1998) reported 
that measures of worry and anxiety were highly correlated, and personal control did not show a differential relationship to anxiety or worry. In the present study, the confirmatory factor analyses by SEM/LV provided convincing evidence of the existence of a common latent inner factor for the five questions and phenomena. The next steps are to interpret and label the latent factor.

Although the five questions looked outwardly at different psychological phenomena (e.g., Davey et al., 1992; Freeston et al., 1996; Stober \& Joormann, 2001; Ehring \& Watkins, 2008; McEvoy et al., 2010), as identified above, other key phrases in the questions are also important: "not able to cut loose” from worries in Q5L5, "impossible to get my mind off” concerns in Q8L1, “end up regretting” in Q8L4, "not able to cut loose” from anxiety in Q8L7, and "impossible to get my mind off” an unpleasant experience in Q8L10. All five phenomena are related to "Being unable to detach from" some mental phenomenon. "Being unable to detach from" was found to be common to worry, bothersome concerns, regret, anxiety, and unpleasant experience in past, present, and future. This common latent inner factor was labeled "Being unable to detach from some concern."

The next step is to investigate what is represented by "some concern" in the latent inner factor. The key meanings of worry, bothersome concern, regret, anxiety, and unpleasant experience suggest that "concerns involving the self" are inspired by and integrated from the five different mental phenomena. Thus, for the time being, the latent inner factor is labeled "Being unable to detach from concerns involving the self” in Figure 1. It is important to keep in mind that this latent inner factor was extracted and found in the US sample. Study 2 will analyze Japanese data to confirm whether or not the latent inner factor also exists in other people from other countries.

\section{Study 2 (Japanese, 2012)}

\subsection{Method}

\subsubsection{Respondents}

A total of 1060 Japanese respondents participated (529 men and 531 women; average age 44.1 years, standard deviation 13.9). Respondents were registered with a social survey company, INTAGE Inc., which has over one million respondents all over Japan. The Total column of Table 7 shows the demographic profile of the respondents. Each year within each age decade was represented by a group of respondents (e.g., for women, 13 20-year-olds, 4 21-year olds, 8 22-year-olds, 11 23-year-olds, and so on). There was no correlation between gender and age, and the demographic distribution of the respondents was statistically ideal for the study of correlations of factors with gender and age.

\subsubsection{Measurement of Variables}

The questionnaire included a brief demographic survey asking gender Q1 and age Q2. Respondents selected one of the following options to indicate their individual annual income Q3: (1) Less than one million JYN (Japanese Yen), (2) Between 1 and 2 million JYN, (3) Between 2 and 3 million JYN, (4)... (9), (10) Between 9 and 10 million JYN, (11)... (12), (13) Between 15 and 20 million, (14) 20 million JYN or more, (15) Don’t know/ prefer not to answer. Respondents selected one of the following options to indicate their level of education Q4: (1) Graduated from primary school, (2) Graduated from junior high school, (3) Graduated from high school or vocational school, (4) Graduated from specialized vocational school or junior college, (5) Graduated from university, (6) Graduated from graduate school.

The questionnaire was the same as that in Study 1, and a latent inner factor was also extracted from the five questions Q5L5, Q8L1, Q8L4, Q8L7, Q8L10, similar to Study 1.

Respondents selected response options in the same manner as those of Study 1.

\subsubsection{Procedures}

The participants were randomly selected from the subscribers of INTAGE Inc., and the questionnaires were sent to them via the Internet. The respondents completed the questionnaires at some time from the 21th to the 24th of February 2012. The respondents received compensation for participating in the survey. All respondents provided informed consent.

The sampling bias of respondents was small, as INTAGE Inc. rigorously performs identity verification and maintenance after respondent registration, procedures which are very similar to those of Survey Sampling International in Study 1. 
3.1.4. Statistical Analysis

Path analysis (SEM: Structural Equation Modeling) was selected, as in Study 1.

\subsection{Results and Discussion}

\subsubsection{Confirmatory Factor Analyses by Structural Equation Modeling of the Latent Variables (SEM/LV)}

Exploratory and confirmatory factor analyses were used to demonstrate the statistical validity of latent factors obtained from the questionnaire, as in Study 1.

While many psychological latent factors were extracted from the eighty questions in the questionnaire in the exploratory analysis, a latent inner factor was extracted from the five questions Q5L5, Q8L1, Q8L4, Q8L7 and Q8L10 (Cronbach's alpha 0.785), as in Study 1. In order to demonstrate the statistical validity of the latent factor, a confirmatory factor analysis was carried out.

The confirmatory factor analysis of the latent factor and structural equation modeling of the latent variables (SEM/LV) were carried out by Amos19. Frequency distributions of responses to Q5L5, Q8L1, Q8L4, Q8L7 and Q8L10 are represented in Tables 7-11 respectively, as cross tabulation scores by gender and age group. As in Study 1, the analysis included the attributes of gender, age, level of education, and annual income, which predict the latent factor, as illustrated in Figure 2. In this path analysis, the relationship with predictivity (not causality) and attributes was similar to Study 1.

In Figure 2, only significant paths are drawn $(p<0.05)$, the latent factor is a latent variable, "Being unable to detach from concerns involving the self," and attributes are observed variables as predictors. Goodness of fit for SEM/LV was acceptable, with RMSEA 0.045 (RMSEA $\leq 0.06$ or less; Hu \& Bentler, 1999), CFI 0.976 and factor loadings 0.266 for Q5L5 ( $p<0.001)$, 0.806 for Q8L1 $(p<0.001)$, 0.739 for Q8L4 $(p<0.001)$, 0.598 for Q8L7 $(p<0.001)$ and 0.846 for Q8L10 $(p<0.001)$. Table 12 provides more detailed information, including the matrix of correlations among all variables along with their means, SDs, correlation coefficients and covariance. The significance tests for the paths are based on the standardized coefficients. $\mathrm{R}^{2}$ was also added on a shoulder of each dependent variable in Figure 2.

Table 7. Cross tabulation scores by gender and age group. Frequency distributions of responses to Q5L5 of Japanese in 2012. Number of respondents that selected the response (numbers in parentheses are its percentage).

\begin{tabular}{ccccccccccccccccc}
\hline \multirow{2}{*}{ Age } & Gender & \multicolumn{2}{c}{$\begin{array}{c}\text { Strongly } \\
\text { agree }\end{array}$} & \multicolumn{2}{c}{ Agree } & \multicolumn{2}{c}{$\begin{array}{c}\text { Somewhat } \\
\text { agree }\end{array}$} & \multicolumn{2}{c}{$\begin{array}{c}\text { Somewhat } \\
\text { disagree }\end{array}$} & Disagree & \multicolumn{2}{c}{$\begin{array}{c}\text { Strongly } \\
\text { disagree }\end{array}$} & Total \\
\hline \multirow{2}{*}{ 20s } & Men & 6 & $(5.6)$ & 23 & $(21.3)$ & 41 & $(38.0)$ & 26 & $(24.1)$ & 12 & $(11.1)$ & 0 & $(0.0)$ & 108 & $(100.0)$ \\
& Women & 3 & $(2.8)$ & 21 & $(19.6)$ & 33 & $(30.8)$ & 28 & $(26.2)$ & 20 & $(18.7)$ & 2 & $(1.9)$ & 107 & $(100.0)$ \\
& Both & 9 & $(4.2)$ & 44 & $(20.5)$ & 74 & $(34.4)$ & 54 & $(25.1)$ & 32 & $(14.9)$ & 2 & $(0.9)$ & 215 & $(100.0)$ \\
$30 s$ & Men & 8 & $(7.5)$ & 10 & $(9.4)$ & 44 & $(41.5)$ & 30 & $(28.3)$ & 13 & $(12.3)$ & 1 & $(0.9)$ & 106 & $(100.0)$ \\
& Women & 3 & $(2.8)$ & 21 & $(19.6)$ & 48 & $(44.9)$ & 25 & $(23.4)$ & 9 & $(8.4)$ & 1 & $(0.9)$ & 107 & $(100.0)$ \\
& Both & 11 & $(5.2)$ & 31 & $(14.6)$ & 92 & $(43.2)$ & 55 & $(25.8)$ & 22 & $(10.3)$ & 2 & $(0.9)$ & 213 & $(100.0)$ \\
$40 s$ & Men & 2 & $(1.8)$ & 23 & $(21.1)$ & 52 & $(47.7)$ & 22 & $(20.2)$ & 10 & $(9.2)$ & 0 & 0.0 & 109 & $(100.0)$ \\
& Women & 2 & $(1.9)$ & 10 & $(9.3)$ & 41 & $(38.3)$ & 40 & $(37.4)$ & 13 & $(12.1)$ & 1 & $(0.9)$ & 107 & $(100.0)$ \\
& Both & 4 & $(1.9)$ & 33 & $(15.3)$ & 93 & $(43.1)$ & 62 & $(28.7)$ & 23 & $(10.6)$ & 1 & $(0.5)$ & 216 & $(100.0)$ \\
& Men & 2 & $(2.0)$ & 12 & $(12.0)$ & 46 & $(46.0)$ & 25 & $(25.0)$ & 15 & $(15.0)$ & 0 & $(0.0)$ & 100 & $(100.0)$ \\
& Women & 0 & $(0.0)$ & 23 & $(21.3)$ & 49 & $(45.4)$ & 23 & $(21.3)$ & 11 & $(10.2)$ & 2 & $(1.9)$ & 108 & $(100.0)$ \\
& Both & 2 & $(1.0)$ & 35 & $(16.8)$ & 95 & $(45.7)$ & 48 & $(23.1)$ & 26 & $(12.5)$ & 2 & $(1.0)$ & 208 & $(100.0)$ \\
& Mos & 1 & $(0.9)$ & 13 & $(12.3)$ & 51 & $(48.1)$ & 26 & $(24.5)$ & 13 & $(12.3)$ & 2 & $(1.9)$ & 106 & $(100.0)$ \\
& Men & Women & 3 & $(2.9)$ & 14 & $(13.7)$ & 38 & $(37.3)$ & 34 & $(33.3)$ & 13 & $(12.7)$ & 0 & $(0.0)$ & 102 & $(100.0)$ \\
& Both & 4 & $(1.9)$ & 27 & $(13.0)$ & 89 & $(42.8)$ & 60 & $(28.8)$ & 26 & $(12.5)$ & 2 & $(1.0)$ & 208 & $(100.0)$ \\
& Men & 19 & $(3.6)$ & 81 & $(15.3)$ & 234 & $(44.2)$ & 129 & $(24.4)$ & 63 & $(11.9)$ & 3 & $(0.6)$ & 529 & $(100.0)$ \\
& Women & 11 & $(2.1)$ & 89 & $(16.8)$ & 209 & $(39.4)$ & 150 & $(28.2)$ & 66 & $(12.4)$ & 6 & $(1.1)$ & 531 & $(100.0)$ \\
& Both & 30 & $(2.8)$ & 170 & $(16.0)$ & 443 & $(41.8)$ & 279 & $(26.3)$ & 129 & $(12.2)$ & 9 & $(0.8)$ & 1060 & $(100.0)$ \\
\hline
\end{tabular}


Table 8. Cross tabulation scores by gender and age group. Frequency distributions of responses to Q8L1 of Japanese in 2012. Number of respondents that selected the response (numbers in parentheses are its percentage).

\begin{tabular}{ccccccccccccccccc}
\hline \multirow{2}{*}{ Age } & Gender & \multicolumn{2}{c}{$\begin{array}{c}\text { Strongly } \\
\text { agree }\end{array}$} & \multicolumn{2}{c}{ Agree } & \multicolumn{2}{c}{$\begin{array}{c}\text { Somewhat } \\
\text { agree }\end{array}$} & $\begin{array}{c}\text { Somewhat } \\
\text { disagree }\end{array}$ & Disagree & \multicolumn{2}{c}{$\begin{array}{c}\text { Strongly } \\
\text { disagree }\end{array}$} & Total \\
\hline \multirow{2}{*}{ 20s } & Men & 27 & $(25.0)$ & 37 & $(34.3)$ & 32 & $(29.6)$ & 11 & $(10.2)$ & 1 & $(0.9)$ & 0 & $(0.0)$ & 108 & $(100.0)$ \\
& Women & 26 & $(24.3)$ & 27 & $(25.2)$ & 34 & $(31.8)$ & 11 & $(10.3)$ & 7 & $(6.5)$ & 2 & $(1.9)$ & 107 & $(100.0)$ \\
& Both & 53 & $(24.7)$ & 64 & $(29.8)$ & 66 & $(30.7)$ & 22 & $(10.2)$ & 8 & $(3.7)$ & 2 & $(0.9)$ & 215 & $(100.0)$ \\
$30 s$ & Men & 18 & $(17.0)$ & 33 & $(31.1)$ & 30 & $(28.3)$ & 16 & $(15.1)$ & 8 & $(7.5)$ & 1 & $(0.9)$ & 106 & $(100.0)$ \\
& Women & 27 & $(25.2)$ & 34 & $(31.8)$ & 32 & $(29.9)$ & 8 & $(7.5)$ & 3 & $(2.8)$ & 3 & $(2.8)$ & 107 & $(100.0)$ \\
& Both & 45 & $(21.1)$ & 67 & $(31.5)$ & 62 & $(29.1)$ & 24 & $(11.3)$ & 11 & $(5.2)$ & 4 & $(1.9)$ & 213 & $(100.0)$ \\
$40 s$ & Men & 13 & $(11.9)$ & 27 & $(24.8)$ & 50 & $(45.9)$ & 13 & $(11.9)$ & 5 & $(4.6)$ & 1 & $(0.9)$ & 109 & $(100.0)$ \\
& Women & 11 & $(10.3)$ & 34 & $(31.8)$ & 45 & $(42.1)$ & 11 & $(10.3)$ & 6 & $(5.6)$ & 0 & $(0.0)$ & 107 & $(100.0)$ \\
& Both & 24 & $(11.1)$ & 61 & $(28.2)$ & 95 & $(44.0)$ & 24 & $(11.1)$ & 11 & $(5.1)$ & 1 & $(0.5)$ & 216 & $(100.0)$ \\
& Men & 5 & $(5.0)$ & 25 & $(25.0)$ & 45 & $(45.0)$ & 19 & $(19.0)$ & 5 & $(5.0)$ & 1 & $(1.0)$ & 100 & $(100.0)$ \\
& Women & 15 & $(13.9)$ & 21 & $(19.4)$ & 48 & $(44.4)$ & 21 & $(19.4)$ & 3 & $(2.8)$ & 0 & $(0.0)$ & 108 & $(100.0)$ \\
& Both & 20 & $(9.6)$ & 46 & $(22.1)$ & 93 & $(44.7)$ & 40 & $(19.2)$ & 8 & $(3.8)$ & 1 & $(0.5)$ & 208 & $(100.0)$ \\
& Men & 3 & $(2.8)$ & 21 & $(19.8)$ & 54 & $(50.9)$ & 18 & $(17.0)$ & 9 & $(8.5)$ & 1 & $(0.9)$ & 106 & $(100.0)$ \\
& Total & Women & 6 & $(5.9)$ & 23 & $(22.5)$ & 45 & $(44.1)$ & 20 & $(19.6)$ & 8 & $(7.8)$ & 0 & $(0.0)$ & 102 & $(100.0)$ \\
& Both & 9 & $(4.3)$ & 44 & $(21.2)$ & 99 & $(47.6)$ & 38 & $(18.3)$ & 17 & $(8.2)$ & 1 & $(0.5)$ & 208 & $(100.0)$ \\
& Men & 66 & $(12.5)$ & 143 & $(27.0)$ & 211 & $(39.9)$ & 77 & $(14.6)$ & 28 & $(5.3)$ & 4 & $(0.8)$ & 529 & $(100.0)$ \\
& Women & 85 & $(16.0)$ & 139 & $(26.2)$ & 204 & $(38.4)$ & 71 & $(13.4)$ & 27 & $(5.1)$ & 5 & $(0.9)$ & 531 & $(100.0)$ \\
& Both & 151 & $(14.2)$ & 282 & $(26.6)$ & 415 & $(39.2)$ & 148 & $(14.0)$ & 55 & $(5.2)$ & 9 & $(0.8)$ & 1060 & $(100.0)$ \\
\hline
\end{tabular}

Table 9. Cross tabulation scores by gender and age group. Frequency distributions of responses to Q8L4 of Japanese in 2012. Number of respondents that selected the response (numbers in parentheses are its percentage).

\begin{tabular}{|c|c|c|c|c|c|c|c|c|c|c|c|c|c|c|c|}
\hline \multirow{2}{*}{$\begin{array}{l}\text { Age } \\
20 s\end{array}$} & \multirow{2}{*}{$\begin{array}{c}\text { Gender } \\
\text { Men }\end{array}$} & \multicolumn{2}{|c|}{$\begin{array}{l}\text { Strongly } \\
\text { agree }\end{array}$} & \multicolumn{2}{|c|}{ Agree } & \multicolumn{2}{|c|}{$\begin{array}{l}\text { Somewhat } \\
\text { agree }\end{array}$} & \multicolumn{2}{|c|}{$\begin{array}{c}\text { Somewhat } \\
\text { disagree }\end{array}$} & \multicolumn{2}{|c|}{ Disagree } & \multicolumn{2}{|c|}{$\begin{array}{l}\text { Strongly } \\
\text { disagree }\end{array}$} & \multicolumn{2}{|c|}{ Total } \\
\hline & & 16 & (14.8) & 34 & (31.5) & 34 & (31.5) & 19 & (17.6) & 2 & (1.9) & 3 & (2.8) & 108 & $(100.0)$ \\
\hline & Women & 7 & (6.5) & 16 & (15.0) & 41 & (38.3) & 21 & (19.6) & 16 & (15.0) & 6 & (5.6) & 107 & (100.0) \\
\hline & Both & 23 & (10.7) & 50 & (23.3) & 75 & (34.9) & 40 & (18.6) & 18 & (8.4) & 9 & $(4.2)$ & 215 & $(100.0)$ \\
\hline \multirow[t]{3}{*}{$30 \mathrm{~s}$} & Men & 11 & (10.4) & 24 & $(22.6)$ & 29 & $(27.4)$ & 25 & $(23.6)$ & 15 & $(14.2)$ & 2 & (1.9) & 106 & (100.0) \\
\hline & Women & 13 & (12.1) & 17 & (15.9) & 35 & (32.7) & 24 & (22.4) & 14 & (13.1) & 4 & (3.7) & 107 & $(100.0)$ \\
\hline & Both & 24 & (11.3) & 41 & (19.2) & 64 & (30.0) & 49 & (23.0) & 29 & (13.6) & 6 & (2.8) & 213 & (100.0) \\
\hline \multirow[t]{3}{*}{$40 \mathrm{~s}$} & Men & 2 & (1.8) & 19 & (17.4) & 48 & $(44.0)$ & 26 & (23.9) & 14 & (12.8) & 0 & 0.0 & 109 & $(100.0)$ \\
\hline & Women & 3 & (2.8) & 13 & $(12.1)$ & 45 & $(42.1)$ & 35 & (32.7) & 8 & (7.5) & 3 & (2.8) & 107 & $(100.0)$ \\
\hline & Both & 5 & (2.3) & 32 & (14.8) & 93 & $(43.1)$ & 61 & (28.2) & 22 & (10.2) & 3 & (1.4) & 216 & $(100.0)$ \\
\hline \multirow[t]{3}{*}{$50 \mathrm{~s}$} & Men & 2 & (2.0) & 11 & (11.0) & 32 & (32.0) & 33 & (33.0) & 19 & (19.0) & 3 & (3.0) & 100 & $(100.0)$ \\
\hline & Women & 2 & (1.9) & 15 & (13.9) & 34 & (31.5) & 35 & (32.4) & 19 & (17.6) & 3 & (2.8) & 108 & $(100.0)$ \\
\hline & Both & 4 & (1.9) & 25 & (12.0) & 66 & (31.7) & 68 & (32.7) & 38 & (18.3) & 6 & (2.9) & 208 & $(100.0)$ \\
\hline \multirow[t]{3}{*}{$60 \mathrm{~s}$} & Men & 1 & (0.9) & 6 & (5.7) & 34 & (32.1) & 45 & $(42.5)$ & 18 & $(17.0)$ & 2 & (1.9) & 106 & $(100.0)$ \\
\hline & Women & 3 & (2.9) & 11 & (10.8) & 27 & (26.5) & 35 & (34.3) & 26 & (25.5) & 0 & 0.0 & 102 & $(100.0)$ \\
\hline & Both & 4 & (1.9) & 17 & (8.2) & 61 & (29.3) & 80 & (38.5) & 44 & $(21.2)$ & 2 & (1.0) & 208 & $(100.0)$ \\
\hline \multirow[t]{3}{*}{ Total } & Men & 32 & (6.0) & 94 & (17.8) & 177 & (33.5) & 148 & (28.0) & 68 & (12.9) & 10 & (1.9) & 529 & $(100.0)$ \\
\hline & Women & 28 & (5.3) & 72 & (13.6) & 182 & (34.3) & 150 & (28.2) & 83 & (15.6) & 16 & (3.0) & 531 & $(100.0)$ \\
\hline & Both & 60 & (5.7) & 166 & (15.7) & 359 & (33.9) & 298 & (28.1) & 151 & (14.2) & 26 & (2.5) & 1060 & (100.0) \\
\hline
\end{tabular}


Table 10. Cross tabulation scores by gender and age group. Frequency distributions of responses to Q8L7 of Japanese in 2012. Number of respondents that selected the response (numbers in parentheses are its percentage).

\begin{tabular}{|c|c|c|c|c|c|c|c|c|c|c|c|c|c|c|c|}
\hline \multirow{2}{*}{$\begin{array}{l}\text { Age } \\
20 \mathrm{~s}\end{array}$} & \multirow{2}{*}{$\begin{array}{c}\text { Gender } \\
\text { Men }\end{array}$} & \multicolumn{2}{|c|}{$\begin{array}{l}\text { Strongly } \\
\text { agree }\end{array}$} & \multicolumn{2}{|c|}{ Agree } & \multicolumn{2}{|c|}{$\begin{array}{l}\text { Somewhat } \\
\text { agree }\end{array}$} & \multicolumn{2}{|c|}{$\begin{array}{c}\text { Somewhat } \\
\text { disagree }\end{array}$} & \multicolumn{2}{|c|}{ Disagree } & \multicolumn{2}{|c|}{$\begin{array}{l}\text { Strongly } \\
\text { disagree }\end{array}$} & \multicolumn{2}{|c|}{ Total } \\
\hline & & 12 & $(11.1)$ & 27 & $(25.0)$ & 39 & (36.1) & 20 & (18.5) & 5 & $(4.6)$ & 5 & (4.6) & 108 & (100.0) \\
\hline & Women & 6 & (5.6) & 20 & (18.7) & 36 & (33.6) & 24 & (22.4) & 19 & (17.8) & 2 & (1.9) & 107 & (100.0) \\
\hline & Both & 18 & (8.4) & 47 & (21.9) & 75 & (34.9) & 44 & (20.5) & 24 & $(11.2)$ & 7 & (3.3) & 215 & (100.0) \\
\hline \multirow[t]{3}{*}{$30 \mathrm{~s}$} & Men & 8 & (7.5) & 15 & $(14.2)$ & 36 & $(34.0)$ & 27 & (25.5) & 15 & $(14.2)$ & 5 & (4.7) & 106 & $(100.0)$ \\
\hline & Women & 12 & $(11.2)$ & 21 & (19.6) & 35 & (32.7) & 24 & $(22.4)$ & 15 & $(14.0)$ & 0 & $(0.0)$ & 107 & (100.0) \\
\hline & Both & 20 & (9.4) & 36 & (16.9) & 71 & (33.3) & 51 & (23.9) & 30 & (14.1) & 5 & (2.3) & 213 & $(100.0)$ \\
\hline \multirow[t]{3}{*}{$40 \mathrm{~s}$} & Men & 3 & (2.8) & 11 & $(10.1)$ & 39 & (35.8) & 38 & (34.9) & 18 & (16.5) & 0 & $(0.0)$ & 109 & (100.0) \\
\hline & Women & 1 & (0.9) & 12 & (11.2) & 42 & (39.3) & 28 & (26.2) & 22 & (20.6) & 2 & (1.9) & 107 & $(100.0)$ \\
\hline & Both & 4 & (1.9) & 23 & (10.6) & 81 & (37.5) & 66 & (30.6) & 40 & (18.5) & 2 & (0.9) & 216 & (100.0) \\
\hline \multirow[t]{3}{*}{$50 \mathrm{~s}$} & Men & 0 & $(0.0)$ & 12 & $(12.0)$ & 38 & $(38.0)$ & 34 & $(34.0)$ & 15 & $(15.0)$ & 1 & $(1.0)$ & 100 & (100.0) \\
\hline & Women & 3 & (2.8) & 11 & $(10.2)$ & 46 & $(42.6)$ & 35 & (32.4) & 10 & (9.3) & 3 & (2.8) & 108 & $(100.0)$ \\
\hline & Both & 3 & (1.4) & 23 & (11.1) & 84 & $(40.4)$ & 69 & (33.2) & 25 & (12.0) & 4 & (1.9) & 208 & (100.0) \\
\hline \multirow[t]{3}{*}{$60 \mathrm{~s}$} & Men & 0 & $(0.0)$ & 8 & (7.5) & 35 & (33.0) & 39 & (36.8) & 22 & (20.8) & 2 & (1.9) & 106 & (100.0) \\
\hline & Women & 3 & (2.9) & 8 & (7.8) & 30 & (29.4) & 32 & (31.4) & 28 & (27.5) & 1 & (1.0) & 102 & (100.0) \\
\hline & Both & 3 & (1.4) & 16 & (7.7) & 65 & (31.3) & 71 & (34.1) & 50 & $(24.0)$ & 3 & (1.4) & 208 & (100.0) \\
\hline \multirow[t]{3}{*}{ Total } & Men & 23 & (4.3) & 73 & (13.8) & 187 & (35.3) & 158 & (29.9) & 75 & $(14.2)$ & 13 & (2.5) & 529 & (100.0) \\
\hline & Women & 25 & (4.7) & 72 & (13.6) & 189 & $(35.6)$ & 143 & (26.9) & 94 & (17.7) & 8 & (1.5) & 531 & (100.0) \\
\hline & Both & 48 & (4.5) & 145 & (13.7) & 376 & (35.5) & 301 & (28.4) & 169 & (15.9) & 21 & (2.0) & 1060 & $(100.0)$ \\
\hline
\end{tabular}

Table 11. Cross tabulation scores by gender and age group. Frequency distributions of responses to Q8L10 of Japanese in 2012. Number of respondents that selected the response (numbers in parentheses are its percentage).

\begin{tabular}{|c|c|c|c|c|c|c|c|c|c|c|c|c|c|c|c|}
\hline \multirow{2}{*}{$\begin{array}{l}\text { Age } \\
\text { 20s }\end{array}$} & \multirow{2}{*}{$\begin{array}{c}\text { Gender } \\
\text { Men }\end{array}$} & \multicolumn{2}{|c|}{$\begin{array}{l}\text { Strongly } \\
\text { agree }\end{array}$} & \multicolumn{2}{|c|}{ Agree } & \multicolumn{2}{|c|}{$\begin{array}{c}\text { Somewhat } \\
\text { agree }\end{array}$} & \multicolumn{2}{|c|}{$\begin{array}{c}\text { Somewhat dis- } \\
\text { agree }\end{array}$} & \multicolumn{2}{|c|}{ Disagree } & \multicolumn{2}{|c|}{$\begin{array}{l}\text { Strongly } \\
\text { disagree }\end{array}$} & \multicolumn{2}{|c|}{ Total } \\
\hline & & 20 & (18.5) & 28 & (25.9) & 44 & (40.7) & 13 & (12.0) & 3 & $(2.8)$ & 0 & $(0.0)$ & 108 & (100.0) \\
\hline & Women & 21 & (19.6) & 23 & (21.5) & 41 & (38.3) & 12 & $(11.2)$ & 8 & (7.5) & 2 & (1.9) & 107 & (100.0) \\
\hline & Both & 41 & (19.1) & 51 & (23.7) & 85 & (39.5) & 25 & (11.6) & 11 & (5.1) & 2 & $(0.9)$ & 215 & (100.0) \\
\hline \multirow[t]{3}{*}{$30 \mathrm{~s}$} & Men & 13 & (12.3) & 22 & (20.8) & 45 & (42.5) & 20 & (18.9) & 5 & $(4.7)$ & 1 & $(0.9)$ & 106 & (100.0) \\
\hline & Women & 24 & $(22.4)$ & 23 & (21.5) & 44 & (41.1) & 9 & $(8.4)$ & 6 & (5.6) & 1 & $(0.9)$ & 107 & (100.0) \\
\hline & Both & 37 & (17.4) & 45 & (21.1) & 89 & (41.8) & 29 & (13.6) & 11 & $(5.2)$ & 2 & $(0.9)$ & 213 & (100.0) \\
\hline \multirow[t]{3}{*}{$40 \mathrm{~s}$} & Men & 7 & $(6.4)$ & 21 & (19.3) & 53 & $(48.6)$ & 23 & (21.1) & 5 & $(4.6)$ & 0 & $(0.0)$ & 109 & (100.0) \\
\hline & Women & 9 & $(8.4)$ & 26 & (24.3) & 53 & (49.5) & 13 & (12.1) & 6 & (5.6) & 0 & $(0.0)$ & 107 & (100.0) \\
\hline & Both & 16 & $(7.4)$ & 47 & (21.8) & 106 & (49.1) & 36 & (16.7) & 11 & (5.1) & 0 & $(0.0)$ & 216 & $(100.0)$ \\
\hline \multirow[t]{3}{*}{$50 \mathrm{~s}$} & Men & 3 & $(3.0)$ & 19 & (19.0) & 45 & $(45.0)$ & 25 & $(25.0)$ & 6 & $(6.0)$ & 2 & $(2.0)$ & 100 & $(100.0)$ \\
\hline & Women & 10 & (9.3) & 22 & (20.4) & 46 & (42.6) & 21 & (19.4) & 8 & $(7.4)$ & 1 & $(0.9)$ & 108 & (100.0) \\
\hline & Both & 13 & (6.3) & 41 & (19.7) & 91 & (43.8) & 46 & (22.1) & 14 & $(6.7)$ & 3 & (1.4) & 208 & (100.0) \\
\hline \multirow[t]{3}{*}{$60 \mathrm{~s}$} & Men & 1 & $(0.9)$ & 13 & (12.3) & 41 & (38.7) & 35 & (33.0) & 14 & $(13.2)$ & 2 & (1.9) & 106 & (100.0) \\
\hline & Women & 7 & (6.9) & 12 & (11.8) & 47 & $(46.1)$ & 28 & (27.5) & 8 & (7.8) & 0 & $(0.0)$ & 102 & (100.0) \\
\hline & Both & 8 & (3.8) & 25 & (12.0) & 88 & (42.3) & 63 & (30.3) & 22 & (10.6) & 2 & (1.0) & 208 & (100.0) \\
\hline \multirow[t]{3}{*}{ Total } & Men & 44 & (8.3) & 103 & (19.5) & 228 & (43.1) & 116 & (21.9) & 33 & $(6.2)$ & 5 & $(0.9)$ & 529 & $(100.0)$ \\
\hline & Women & 71 & (13.4) & 106 & (20.0) & 231 & (43.5) & 83 & (15.6) & 36 & (6.8) & 4 & $(0.8)$ & 531 & (100.0) \\
\hline & Both & 115 & (10.8) & 209 & (19.7) & 459 & (43.3) & 199 & (18.8) & 69 & (6.5) & 9 & $(0.8)$ & 1060 & (100.0) \\
\hline
\end{tabular}


Table 12. Mean, standard deviation, correlation coefficient (Coef.) and covariance (Cova.) for Q1, Q2, Q4, Q3, Q5L5, Q8L1, Q8L4, Q8L7 and Q8L10 of Japanese in 2012.

\begin{tabular}{|c|c|c|c|c|c|c|c|c|c|c|}
\hline & & $\begin{array}{c}\text { Q1 } \\
\text { Gender }\end{array}$ & $\begin{array}{l}\text { Q2 } \\
\text { Age }\end{array}$ & $\begin{array}{l}\text { Q4 Level of } \\
\text { education }\end{array}$ & $\begin{array}{l}\text { Q3 Annual } \\
\text { income }\end{array}$ & Q5L5 & Q8L1 & Q8L4 & Q8L7 & Q8L10 \\
\hline \multicolumn{2}{|l|}{ Means } & 1.50 & 44.12 & 3.97 & 3.27 & 3.32 & 2.72 & 3.37 & 3.43 & 2.93 \\
\hline \multicolumn{2}{|l|}{ Standard devi. } & 0.500 & 13.89 & 1.008 & 2.636 & 1.001 & 1.087 & 1.149 & 1.109 & 1.073 \\
\hline \multirow{2}{*}{ Q1. Gender } & Coef. & 1.000 & -0.02 & -0.179 & -0.489 & 0.041 & -0.033 & 0.065 & 0.004 & -0.76 \\
\hline & Cova. & 0.250 & -0.1 & -0.09 & -0.645 & 0.020 & -0.018 & 0.037 & 0.002 & -0.041 \\
\hline \multirow{2}{*}{ Q2. Age } & Coef. & & 1.000 & -0.056 & $0.187^{* *}$ & 0.049 & $0.216^{* *}$ & $0.226^{*}$ & $0.199^{* *}$ & $0.244^{* *}$ \\
\hline & Cova. & & 192.8 & -0.789 & 6.849 & 0.676 & 3.257 & 3.598 & 3.069 & 3.635 \\
\hline \multirow{2}{*}{$\begin{array}{l}\text { Q4. Level of } \\
\text { education }\end{array}$} & Coef. & & & 1.000 & $0.235^{* *}$ & -0.01 & -0.021 & -0.004 & 0.011 & 0.012 \\
\hline & Cova. & & & 1.016 & 0.625 & -0.01 & -0.023 & -0.004 & 0.012 & 0.013 \\
\hline \multirow{2}{*}{$\begin{array}{l}\text { Q3. Annual } \\
\text { income }\end{array}$} & Coef. & & & & 1.000 & -0.065 & $0.110^{* *}$ & $0.094^{* *}$ & 0.054 & $0.109^{* *}$ \\
\hline & Cova. & & & & 6.949 & -0.17 & 0.315 & 0.285 & 0.157 & 0.309 \\
\hline \multirow{2}{*}{ Q5L5 } & Coef. & & & & & 1.000 & $0.199^{* *}$ & $0.192^{* *}$ & $0.172^{* *}$ & $0.241^{* *}$ \\
\hline & Cova. & & & & & 1.002 & 0.216 & 0.220 & 0.191 & 0.258 \\
\hline \multirow{2}{*}{ Q8L1 } & Coef. & & & & & & 1.000 & $0.581^{* *}$ & $0.475^{* *}$ & $0.695^{* *}$ \\
\hline & Cova. & & & & & & 1.181 & 0.725 & 0.572 & 0.810 \\
\hline \multirow{2}{*}{ Q8L4 } & Coef. & & & & & & & 1.000 & $0.496^{* *}$ & $0.619^{* * *}$ \\
\hline & Cova. & & & & & & & 1.319 & 0.631 & 0.763 \\
\hline \multirow{2}{*}{ Q8L7 } & Coef. & & & & & & & & 1.000 & $0.479^{* *}$ \\
\hline & Cova. & & & & & & & & 1.230 & 0.570 \\
\hline \multirow{2}{*}{ Q8L10 } & Coef. & & & & & & & & & 1.000 \\
\hline & Cova. & & & & & & & & & 1.152 \\
\hline
\end{tabular}

Because the sample size of Study 2 was greater than 1000 participants, which is a considerably large sample, chi-square was inappropriate. It was reasonable to adopt the SEM and evaluate the goodness of fit for modeling as acceptable because the weighted sum of Q5, Q8L1, Q8L4, Q8L7 and Q8L10 was similar to Study 1, Cronbach's alpha was higher, the number of observational variables was larger, and RMSEA (lower than 0.06) was useful (Hu \& Bentler, 1999).

In summary, a confirmatory factor analysis by SEM/LV verified that a common latent inner factor could be extracted from the five questions in the Japanese as well as the US sample.

\subsubsection{The Same Latent Inner Factor Was Found in Japanese Data}

The same common latent inner factor, "Being unable to detach from concerns involving the self," was extracted from both the US and Japanese samples, indicating that the latent inner factor exists in the minds of both US and Japanese people. It is very well known that many substantial cultural variations have been identified between independent (e.g., Euro-American) and interdependent(e.g., Asian) cultures (Uchida et al., 2004; Uchida et al., 2008; Uchida et al., 2009); however, the present study has obtained the same inner latent factor in countries representing such different cultures. Can the same latent inner factor be extracted from the combined data of US and Japanese respondents? To confirm the existence of the latent inner factor, combined data will be statistically analyzed in Study 3.

\section{Study 3 (Combined US and Japanese Data)}

\subsection{Method}

\subsubsection{Respondents}

In order to carry out statistical analyses, data of Studies 1 and 2 were simply combined. The total number of 


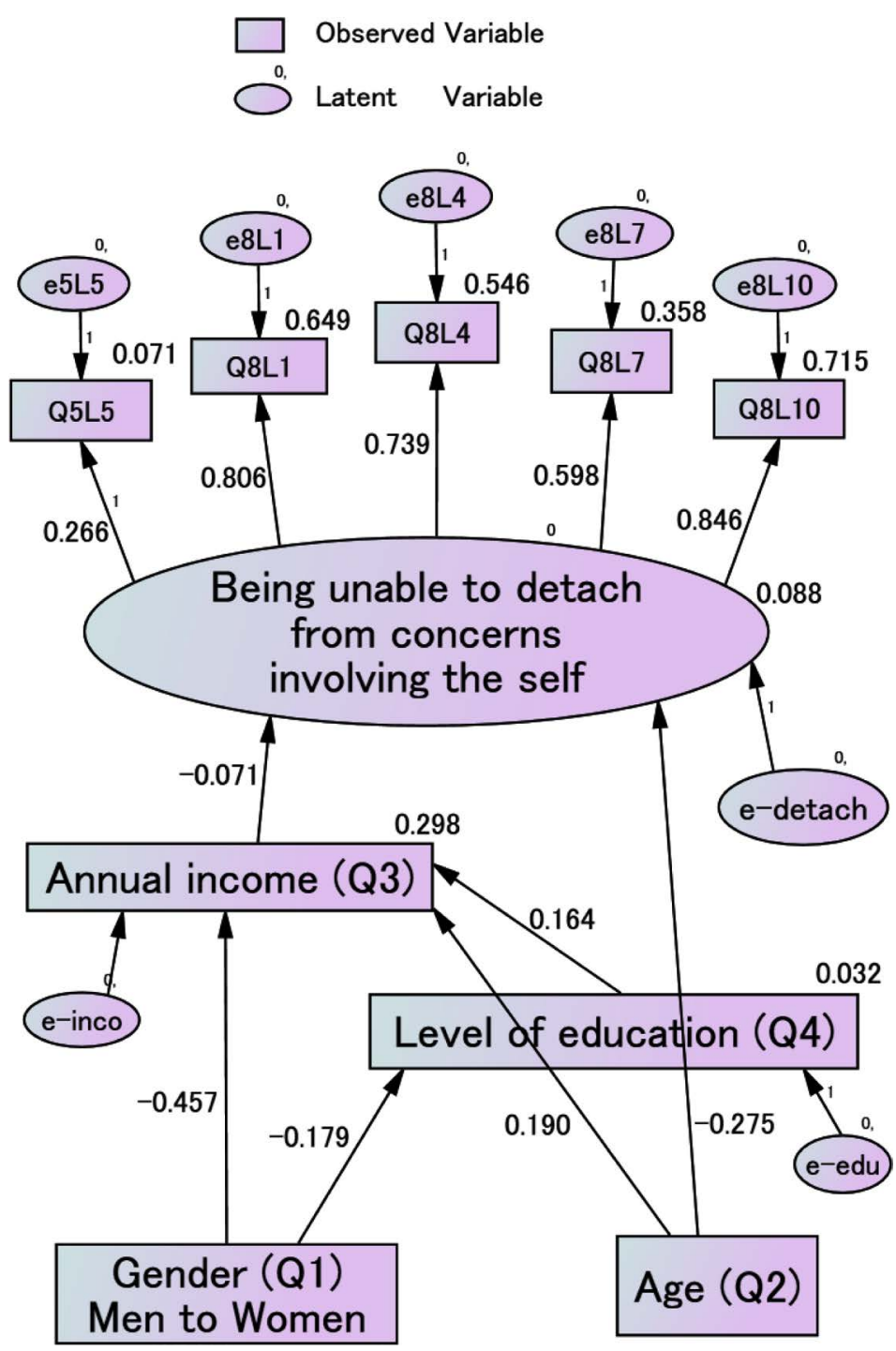

Figure 2. Confirmatory factor analysis of "Being unable to detach from concerns involving the self” and SEM/LV including the four attributes (gender, age, level of education and annual income) that predicted the factor, in the Japanese sample. Correlation coefficients between "Being unable to detach from concerns involving the self" and the four attributes are written only for paths with $p<0.05$. The questions were as follows: [Q1]: Gender (Men to Women); [Q2]: Age; [Q3]: Annual income; [Q4]: Level of education, [Q5L5] indicated respondents' inability to cut loose from worries even when things were certainly found not to go right for them. [Q8L1] indicated respondents' inability to get their minds off concerns that are bothering them. [Q8L4] indicated respondents' inability to not end up regretting something forever. [Q8L7] indicated respondents' inability to cut loose from uneasy occurrences and anxiety which may happen in the future. [Q8L10] indicated respondents' inability to get their minds off an unpleasant experience once they have had it. Factor loadings for [Q5L5], [Q8L1] [Q8L4] [Q8L7] and [Q8L10] (all $p<0.001$ ) are indicated along the paths. $\mathrm{R}^{2}$ is indicated on shoulder of each dependent variable.

respondents was 2185 (1069 men and 1116 women; average age 44.4 years, standard deviation 14.0). As in Studies 1 and 2, there was no correlation between gender and age.

\subsubsection{Measurement of Variables}

An identical questionnaire to that used in Studies 1 and 2 was used in Study 3. A brief demographic survey inquired about gender, Q1 and age, Q2. The latent inner factor was assessed by five questions Q5L5, Q8L1, Q8L4, Q8L7, and Q8L10, similar to Studies 1 and 2. Respondents selected response options identically to those in Studies 1 and 2 . 


\subsubsection{Procedures}

The procedures and respondents in Study 3 were identical to those in Studies 1 and 2. All respondents gave their informed consent before participating in the study. The sampling bias of respondents was small. Survey Sampling International and INTAGE Inc. rigorously performed identity verification and maintenance after the registration of the respondents in Studies 1 and 2.

\subsubsection{Statistical Analysis}

Path analysis (SEM: Structural Equation Modeling) was again selected.

\subsection{Results and Discussion}

\subsubsection{Confirmatory Factor Analyses by Structural Equation Modeling of the Latent Variables} (SEM/LV)

Exploratory and confirmatory factor analyses were used to demonstrate the statistical validity of latent factors obtained from the questionnaire, as in Studies 1 and 2.

Again, many psychological latent factors were initially extracted from the eighty questions in the questionnaire, but a latent inner factor was extracted from five questions Q5L5, Q8L1, Q8L4, Q8L7 and Q8L10 (Cronbach's alpha 0.822). In order to demonstrate the statistical validity of the latent factor, a confirmatory factor analysis of the latent factor and structural equation modeling of the latent variable (SEM/LV) were carried out by Amos 19. Unlike Studies 1 and 2, the analysis included only gender and age as attributes which predicted the latent factor, as illustrated in Figure 3. Because currency rates in the US and Japan are changing everyday, and education content is substantially different in the US and Japan, the level of education and annual income are not comparable as absolute values in the two countries. Therefore, level of education and annual income as attributes were deleted from SEM/LV in Figure 3. In this path analysis, the relationship with predictivity (not causality) and attributes was similar to Studies 1 and 2.

In Figure 3, only significant paths are drawn $(p<0.05)$, the latent factor is a latent variable "Being unable to detach from concerns involving the self," and attributes are observed variables as predictors. Goodness of fit for SEM/LV was acceptable, with RMSEA 0.058 (RMSEA $\leq 0.06$ or less; Hu \& Bentler, 1999), CFI 0.974, and factor loadings 0.489 for Q5L5 ( $p<0.001)$, 0.776 for Q8L1 ( $p<0.001)$, 0.698 for Q8L4 $(p<0.001), 0.676$ for Q8L7 $(p<0.001)$ and 0.836 for Q8L10 $(p<0.001)$. More detailed information is shown in Table 13, including the matrix of correlations among all variables along with their means, SDs, correlation coefficients and covariance. The significance tests for the paths are based on the standardized coefficients. $\mathrm{R}^{2}$ was also added on a shoulder of each dependent variable in Figure 3.

Since the sample size of Study 3 was over 2000 participants, a considerably large sample, it was again inappropriate to use chi-square, and the weighted sum of Q5, Q8L1, Q8L4, Q8L7 and Q8L10, Cronbach's alpha, the number of observational variables, and RMSEA made it acceptable to adopt the SEM and evaluate the goodness of fit for modeling.

In the combined US and Japanese data, the confirmatory factor analyses by SEM/LV revealed that a common latent inner factor could be extracted from the five questions, as in the US-only and Japanese-only samples.

\subsubsection{The Same Latent Inner Factor in the Combined US-Japanese Data}

Although the Internet questionnaire surveys in Study 1 and Study 2 were carried out in different places and different times, the tendency revealed in the combined data was the same as that with each single data set. That the same inner latent factor was obtained from the combined data of such different cultural (US and Japanese) variations (Uchida et al., 2004; Uchida et al., 2008; Uchida et al., 2009) suggests that the latent inner factor exists in minds of people of any country, although more data from other countries are necessary to confirm this. Thus, it appears that worry, bothersome concern, regret, anxiety, and unpleasant experience are connected to the latent inner factor labeled "Being unable to detach from concerns involving the self" for the US-only sample, for the Japanese-only sample, and also for the combined data of both countries.

\section{Correlations of Four Attributes with the Latent Inner Factor}

The correlations between four participant attributes (gender, age, level of education, and annual income) and the latent inner factor "Being unable to detach from concerns involving the self" were examined. 


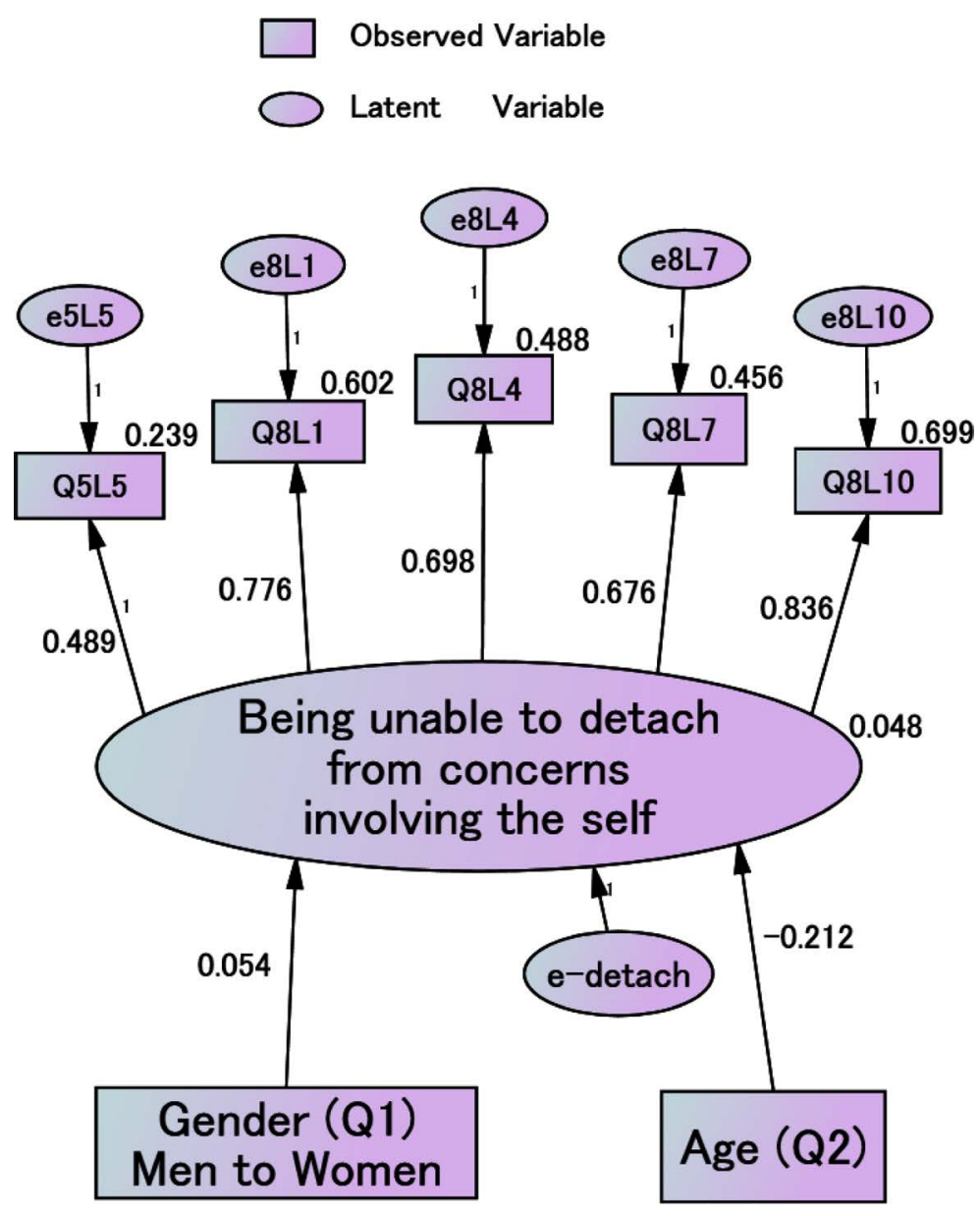

Figure 3. Confirmatory factor analysis of "Being unable to detach from concerns involving the self” and SEM/LV including the four attributes (gender, age, level of education and annual income) that predicted the factor, in the combined US and Japanese data. Correlation coefficients between "Being unable to detach from concerns involving the self" and the four attributes are written only for paths with $p<0.05$. The questions were as follows: [Q1]: Gender (Men to Women); [Q2]: Age; [Q3]: Annual income; [Q4]: Level of education, [Q5L5] indicated respondents' inability to cut loose from worries even when things were certainly found not to go right for them. [Q8L1] indicated respondents' inability to get their minds off concerns that are bothering them. [Q8L4] indicated respondents' inability to not end up regretting something forever. [Q8L7] indicated respondents' inability to cut loose from uneasy occurrences and anxiety which may happen in the future. [Q8L10] indicated respondents' inability to get their minds off an unpleasant experience once they have had it. Factor loadings for [Q5L5], [Q8L1] [Q8L4] [Q8L7] and [Q8L10] (all $p<0.001$ ) are indicated along the paths. $\mathrm{R}^{2}$ is indicated on shoulder of each dependent variable.

\subsection{Correlation with Gender}

Path coefficients between gender (men to women) and "Being unable to detach from concerns involving the self" were $+0.086,+0.032(=-0.457 \times-0.071)$, and $+0.054(p<0.05)$ for US, Japanese, and combined US-Japanese data shown in Figures 1-3, respectively, indicating that women were more unable to detach from concerns involving the self than were men in both the US and Japanese samples. It is notable that the same tendency was obtained for the correlation with gender in both independent (e.g., Euro-American) and interdependent (e.g., Asian) cultures.

\subsection{Correlation with Age}

Path coefficients between age and "Being unable to detach from concerns involving the self" were -0.149 , $-0.275(\&-0.013=0.190 \times-0.071$ as indirect path), and $-0.212(p<0.05)$ for US, Japanese, and combined US-Japanese data shown in Figures 1-3, respectively. Younger people, as compared to older people, were more 
Table 13. Mean, standard deviation, correlation coefficient and covariance for Q1, Q2, Q5L5, Q8L1, Q8L4, Q8L7 and Q8L10 of the combined data for US White and Japanese in 2012.

\begin{tabular}{|c|c|c|c|c|c|c|c|c|}
\hline & & Q1 Gender & Q2 Age & Q5L5 & Q8L1 & Q8L4 & Q8L7 & Q8L10 \\
\hline & Means & 1.51 & 44.44 & 3.24 & 2.79 & 3.6 & 3.48 & 3.18 \\
\hline & lard deviation & 0.500 & 14.002 & 1.223 & 1.198 & 1.274 & 1.213 & 1.225 \\
\hline \multirow{2}{*}{ Q1. Gender } & Correlation coefficient & 1.000 & -0.011 & -0.024 & -0.064 & 0.041 & -0.046 & -0.069 \\
\hline & Covariance & 0.250 & -0.079 & -0.014 & -0.038 & 0.026 & -0.028 & -0.043 \\
\hline \multirow{2}{*}{ Q2. Age } & Correlation coefficient & & 1.000 & $0.059^{* *}$ & $0.154^{* *}$ & $0.138^{* *}$ & $0.177^{* *}$ & $0.185^{* *}$ \\
\hline & Covariance & & 196.1 & 1.012 & 2.95 & 2.463 & 3.002 & 3.181 \\
\hline \multirow{2}{*}{ Q5L5 } & Correlation coefficient & & & 1.000 & $0.411^{* *}$ & $0.297^{* *}$ & $0.394^{* *}$ & $0.383^{* *}$ \\
\hline & Covariance & & & 1.496 & 0.602 & 0.463 & 0.585 & 0.574 \\
\hline \multirow{2}{*}{ Q8L1 } & Correlation coefficient & & & & 1.000 & $0.517^{* *}$ & $0.527^{* *}$ & $0.653^{* *}$ \\
\hline & Covariance & & & & 1.436 & 0.789 & 0.766 & 0.958 \\
\hline \multirow{2}{*}{ Q8L4 } & Correlation coefficient & & & & & 1.000 & $0.481^{* *}$ & $0.610^{* *}$ \\
\hline & Covariance & & & & & 1.622 & 0.743 & 0.951 \\
\hline \multirow{2}{*}{ Q8L7 } & Correlation coefficient & & & & & & 1.000 & $0.541^{* *}$ \\
\hline & Covariance & & & & & & 1.472 & 0.804 \\
\hline \multirow{2}{*}{ Q8L10 } & Correlation coefficient & & & & & & & 1.000 \\
\hline & Covariance & & & & & & & 1.5 \\
\hline
\end{tabular}

${ }^{* *} p<0.01$.

unable to detach from concerns involving the self in both the US and Japanese samples. Again, the same tendency was obtained for the correlation with age in both independent (e.g., Euro-American) and interdependent (e.g., Asian) cultures. Since older people have had many more life experiences than younger people, older people may have learned more about how to be able to detach from concerns involving the self than younger people. The result suggests that this tendency with age may be general for any country, although more data from other countries are necessary to confirm this.

\subsection{Correlation with Level of Education}

Path coefficients between level of education and "Being unable to detach from concerns involving the self" were -0.075 and $-0.012(=-0.071 \times 0.164)(p<0.05)$ for US and Japanese, as shown in Figure 1 and Figure 2 , respectively. People with lower levels of education were less able to detach from concerns involving the self than were people with higher levels of education, for both US and Japanese samples. The same tendency was obtained for the correlation with levels of education in both cultures, perhaps because education may provide some positive effects for "Being able to detach from concerns involving the self".

\subsection{Correlation with Annual Income}

The path coefficient between annual income and "Being unable to detach from concerns involving the self” was $-0.071(p<0.05)$ for the Japanese sample, as shown in Figure 2. On the other hand, there was no significant correlation for the US sample, as shown in Figure 1. There may be little or a little relation between annual income and "Being unable to detach from concerns involving the self".

\subsection{More Convincing Evidence of the Existence of the Common Latent Inner Factor for the Five Phenomena}

It was first found that women, younger people and people with lower levels of education as compared to men, older people, and people with higher levels of education were more unable to detach from concerns involving the self in both the US and Japanese samples. It is notable and provides certain and more convincing evidence of the existence of the common latent inner factor for the five phenomena that the same tendency was obtained for 
the correlation with gender, age and level of education in both independent (US) and interdependent (Japan) cultures.

\section{General Discussion}

When you regret, worry about, or are anxious about something, what is it that you regret, worry about, or are anxious about? It may be something that happened to you in the past, is happening to you at the present time, or will happen to you in the future. If what happened, is happening, or will happen is that things go right for you, you do not have any regret, worry, or anxiety. But, things do not go right for you, you may experience regret, worry, or anxiety. Then you will try to change the situation so goes right for you. And if you fail, you will likely try again. However, suppose that you finally understand that the situation can't be changed any more. At that time, what do you do? Although all you need to do is to prepare and carry out actions that are necessary to make progress, it may happen that you do not have the positive will or inclination to prepare and act on the things that are necessary to make progress, because you are not able to detach from the concerns that arise when things do not go right for you. In this situation, you are inclined to become irritated, to worry, to be anxious and regretful, and to negatively ruminate and/or engage in repetitive negative thinking. Since all of these concerns certainly involve the self (because the concerns are connected to things which do not go right for you), each such concern (regret, worry, anxiety, irritation, negative rumination and engagement in repetitive negative thinking) is one aspect of, and derives from, “concerns involving the self”, which exist only in your mind (“Omoi” in Japanese).

At that time, in order to be able to detach from "concerns involving the self", you should face squarely the worry, bothersome concerns, regret, anxiety, negative ruminations and/or repetitive negative thinking, which are derived from "concerns involving the self”. However, it is usually difficult for people to face such concerns squarely, because people, including many psychologists, think that worry, bothersome concerns, regret, anxiety, negative ruminations and/or repetitive negative thinking are different phenomena one another, and do not understand that they are all derived from "concerns involving the self" in one's mind ("Omoi”). If you can face squarely "concerns involving the self”, you have the chance to deal with them properly, and detach yourself from such concerns. Then, when your mind is no longer a prisoner of "concerns involving the self”, you can have the positive will to prepare and carry out the actions that are necessary to move forward.

About one hundred years ago (in 1933), the 32nd American President Franklin D. Roosevelt said, "The only thing we have to fear is fear itself-nameless, unreasoning, unjustified terror which paralyzes needed efforts to convert retreat into advance." What is the difference between the usual fear that people speak of and fear itself ("Kyohfukan" in Japanese), which Franklin Roosevelt refers to? He is saying that we should be afraid of the fear itself that prevents people from doing things that are necessary to make progress. In other words, he means that at first you should recognize fear itself, which is usually difficult to recognize because of its nature as nameless, unreasoning, and unjustified, and then you should face squarely fear itself, which is one aspect of, and derives from the "concerns involving the self.” Because fear itself does not actually exist in reality, but is only a mental artifact, if and when you understand its nature as a mental artifact and can face it squarely, you can treat it properly and finally detach from it, and can take the practical action that is needed to move forward. Franklin Roosevelt had great insight into psychology and philosophy with regard to "Being able to detach from concerns involving the self, ('Omoikiri' in Japanese)" in which "The only thing we have to fear is fear itself” is comprehensively included. Following his speech, we can say, "The only thing we have to fear is fear itself, regret itself, worry itself, and anxiety itself, which are all unreasonable and unjustified mental artifacts, and derived from 'concerns involving the self'.” Roosevelt also said "Men are not prisoners of fate, but only prisoners of their own minds.” This reference to "their own minds” must be equivalent to "concerns involving the self”.

\subsection{Limitations of the Study}

This research is based on Internet survey of peoples' subjective opinions and attitudes, which were assessed by a questionnaire. It was based on responses of people living in the US and Japan. It would be desirable to conduct the identical study in other countries. Also, actual experiments on peoples' action were not conducted in this study. Therefore, it would be desirable to conduct similar research on peoples’ actions.

\subsection{Directions for Future Research}

An interpretation of the present results in terms of positive psychology (Seligman \& Csikszentmihalyi, 2000; 
Seligman \& Pawelski, 2003) and in the study of ordinary people, rather than clinical patients, suggests that the label of the latent inner factor can be reversed in a positive way that is related to happiness, as "Being able to detach from concerns involving the self". This reversal can be achieved by reversing the numbers of the response alternatives of the five questions. In this way, two latent inner factors, "Being unable to detach from concerns involving the self" and "Being able to detach from concerns involving the self" can be introspectively examined.

Csikszentmihalyi $(1978,1990,1997)$ described flow. Although there appears to be a relationship between flow and the latent inner factor labeled "Being able to detach from concerns involving the self," further research about this relationship is necessary. It is also important to investigate which among the multiple intelligences studied by Gardner (1999) is closely related to obtaining the state of "Being able to detach from concerns involving the self." The most likely one is intrapersonal intelligence, which involves introspectiveness, selfreflection, and awareness of the inner world of the self. Also relevant is research about the relationship between mindfulness meditation and well-being (Brown \& Ryan, 2003; Manoka, 2011; Ziaian et al., 2015). While mindfulness meditation may be thought as one of the most effective methods for people to achieve the inner state of "Being able to detach from concerns involving the self ('Omoikiri')", further study is necessary, including how to improve mindfulness meditation.

Hayase and Ura (2015) reported a study of the distinction between ownership and taking action for genuine human happiness, rather than episodic happiness (Raibley, 2012). They pointed out that some recent philosophical studies have argued that there is no self-ownership of one's own body, to say nothing of material ownership (Pendlebury et al., 2001; Uyl \& Rasmussen, 2003; Taylor, 2005; Curchin, 2007; Ypi, 2011), and that further research is necessary to more fully address the distinction of self-ownership and no ownership, both psychologically and philosophically.

In terms of the present study, does the state of "Being unable to detach from concerns involving the self" mean that one psychologically owns "concerns involving the self"? This is a profound question that awaits future research.

\section{Acknowledgements}

The author would like to thank Professor M. Ura of Otemon University, Professor K. Adachi of Osaka University, and several anonymous reviewers for valuable discussions. The author also thanks Dr. Y. Takebayashi and Dr. K. Tanaka of Hiroshima University for references to relevant literature.

\section{References}

Bergman, R. L., \& Craske, M. G. (2000). Verbalization and Imagery during Worry Activity. Depression and Anxiety, 11, 169-174. http://dx.doi.org/10.1002/1520-6394(2000)11:4<169::AID-DA4>3.0.CO;2-V

Brosschot, J. F., Gerin, W., \& Thayer, J. F. (2006). The Perseverative Cognition Hypothesis: A Review of Worry, Prolonged Stress-Related Physiological Activation, and Health. Journal of Psychosomatic Research, 60, 113-124. http://dx.doi.org/10.1016/j.jpsychores.2005.06.074

Brown, K. W., \& Ryan, R. M. (2003). The Benefits of Being Present: Mindfulness and Its Role in Psychological Well-Being. Journal of Personality and social Psychology, 84, 822-848. http://dx.doi.org/10.1037/0022-3514.84.4.822

Carleton, R. N., Mulvogue, M. K., Thibodeau, M. A., McCabe, R. E., Antony, M., \& Asmundson, G. J. G. (2012). Increasingly Certain about Uncertainty: Intolerance of Uncertainty across Anxiety and Depression. Journal of Anxiety Disorders, 26, 468-479. http://dx.doi.org/10.1016/j.janxdis.2012.01.011

Carleton, R. N., Sharpe, D., \& Asmunden, G. J. G. (2007). Anxiety Sensitivity and Intolerance of Uncertainty: Requisites of the Fundamental Fear? Behaviour Research and Therapy, 45, 2307-2316. http://dx.doi.org/10.1016/j.brat.2007.04.006

Csikszentmihalyi, M. (1978). The Stream of Consciousness. New York: Plenum.

Csikszentmihalyi, M. (1990). Flow: The Psychology of Optimal Experience. New York: Harper and Row.

Csikszentmihalyi, M. (1997). Finding Flow: The Psychology of Engagement with Everyday Life. New York: Basic Books.

Curchin, K. (2007). Debate: Evading the Paradox of Universal Self-Ownership. The Journal of Political Philosophy, 15, 484-494. http://dx.doi.org/10.1111/j.1467-9760.2007.00288.x

Davey, G. C. L., Hampton J., Farrell, J., \& Davidson, S. (1992). Some Characteristics of Worrying: Evidence for Worrying and Anxiety as Separate Constructs. Personality and Individual Differences, 13, 133-147.

http://dx.doi.org/10.1016/0191-8869(92)90036-O 
Diener, E., Horwitz, E. J., \& Emmons, R. A. (1985). Happiness of the Very Wealthy. Social Indicators Research, 16, 263274. http://dx.doi.org/10.1007/BF00415126

Diener, E., Robert, A. E., Randy, J. L., \& Sharon, G. (1985). The Satisfaction with Life Scale. Journal of Personality Assessment, 49, 71-75. http://dx.doi.org/10.1207/s15327752jpa4901_13

Ehring, T., \& Watkins, E. R. (2008). Repetitive Negative Thinking as a Transdiagnostic Process. International Journal of Cognitive Therapy, 1, 192-205. http://dx.doi.org/10.1521/ijct.2008.1.3.192

Ehring, T., Zetsche, U., Weidacker, K., Wahl, K., Schonfeld, S., \& Ehlers, A. (2011). The Perseverative Thinking Questionnaire (PTQ): Validation of a Content-Independent Measure of Repetitive Negative Thinking. Journal of Behavior Therapy and Experimental Psychiatry, 42, 225-232. http://dx.doi.org/10.1016/j.jbtep.2010.12.003

Freeston, M. H., Dugas, M. J., \& Ladouceur, R. (1996). Thoughts, Images, Worry, and Anxiety. Cognitive Therapy and Research, 20, 265-273. http://dx.doi.org/10.1007/BF02229237

Freeston, M. H., Rheaume, J., Letarte, H., Dugas, M. J., \& Ladouceur, R. (1994). Why Do People Worry? Personality and Individual Differences, 17, 791-802. http://dx.doi.org/10.1016/0191-8869(94)90048-5

Gardner, H. (1999). Intelligence Reframed: Multiple Intelligences for the 21st century. New York: Basic Books.

Hayase, K., \& Ura, M. (2015). Ownership or Taking Action: Which Is More Important for Happiness? Psychology, 6, 734-751. http://dx.doi.org/10.4236/psych.2015.66072

Hoffman, D. L., Dukes, E. M., \& Wittchen, H.-U. (2008). Human and Economic Burden of Generalized Anxiety Disorder. Depression and Anxiety, 25, 72-90. http://dx.doi.org/10.1002/da.20257

Hu, L., \& Bentler, P. M. (1999). Cutoff Criteria for Fit Indexes in Covariance Structure Analysis: Conventional Criteria versusNew Alternatives. Structural Equation Modeling, 6, 1-55. http://dx.doi.org/10.1080/10705519909540118

Komiya, A., Miyamoto, Y., Watabe, M., \& Kusumi, T. (2012). Cultural Grounding of Regret: Regret in Self and Interpersonal Contexts. Cognition \& Emotion, 25, 1121-1130. http://dx.doi.org/10.1080/02699931.2010.516962

McEvoy, P. M., Mahoney, A. E. J., \& Moulds, M. L. (2010). Are Worry, Rumination, and Post-Event Processing One and the Same? Development of the Repetitive Thinking Questionnaire. Journal of Anxiety Disorders, 24, 509-519. http://dx.doi.org/10.1016/j.janxdis.2010.03.008

Manoka, R. (2011). Meditation, Mindfulness and Mind-Emptiness. Acta Neuropsychiatrica, 23, 46-47. http://dx.doi.org/10.1111/j.1601-5215.2010.00519.x

Nickerson, C., Schwarz, N., \& Diener, Ed., The Gallup Organization (2007). Financial Aspirations, Financial Success, and Overall Life Satisfaction: Who? And How? Journal of Happiness Studies, 8, 467-515. http://dx.doi.org/10.1007/s10902-006-9026-1

Nolen-Hoeksema, S., Blair, E. W., \& Sonja L. (2008). Rethinking Rumination. Perspectives of Psychological Science, 3, 400-424. http://dx.doi.org/10.1111/j.1745-6924.2008.00088.x

Oishi, S., \& Sullivan, H. W. (2006). The Predictive Value of Daily vs. Retrospective Well-Being Judgments in Relationship Stability. Journal of Experimental Social Psychology, 42, 460-470. http://dx.doi.org/10.1016/j.jesp.2005.07.001

Pendlebury, M., Hudson, P., \& Moellendorf, D. (2001). Capitalist Exploitation, Self-Ownership, and Equality. The Philosophical Forum, 32, 207-220. http://dx.doi.org/10.1111/0031-806X.00062

Raibley, J. R. (2012). Happiness Is Not Well-Being. Journal of Happiness Studies, 13, 1105-1129. http://dx.doi.org/10.1007/s10902-011-9309-z

Roese, N. L., Epstude, K., Fessel, F., Morrison, M., Smallman, R., Summerville, A., Galinsky, A., \& Segerstrom, S. (2009). Repetitive Regret, Depression, and Anxiety: Findings from a Nationally Representative Survey. Journal of Social and Clinical Psychology, 28, 671-688. http://dx.doi.org/10.1521/jscp.2009.28.6.671

Saffrey, C., Summerville, A., \& Roese, N. J. (2008). Praise for Regret: People Value Regret above Other Negative Emotions. Motivation and Emotion, 32, 46-54. http://dx.doi.org/10.1007/s11031-008-9082-4

Schimmack, U., \& Oishi, S. (2005). The Influence of Chronically Accessible and Temporarily Accessible Information on Life Satisfaction Judgment. Journal of Personality and Social Psychology, 89, 395-406. http://dx.doi.org/10.1037/0022-3514.89.3.395

Seligman, M. E. P., \& Csikszentmihalyi, M. (2000). Positive Psychology: An Introduction. American Psychologist, 55, 5-14. http://dx.doi.org/10.1037/0003-066X.55.1.5

Seligman, M. E. P., \& Pawelski, J. O. (2003). Positive Psychology: FAQs. Psychological Inquiry, 14, 159-163.

Stober, J., \& Joormann, J. (2001). Worry, Procrastination, and Perfectionism: Differentiating Amount of Worry, Pathological Worry, Anxiety, and Depression. Cognitive Therapy and Research, 25, 49-60. http://dx.doi.org/10.1023/A:1026474715384

Stokes, C., \& Hirsch, C. R. (2010). Engaging in Imagery versus Verbal Processing of Worry: Impact on Negative Intrusions 
in High Worriers. Behaviour Research and Therapy, 48, 418-423. http://dx.doi.org/10.1016/j.brat.2009.12.011

Sugiura Y. (2007). Responsibility to Continue Thinking and Worrying: Evidence of Incremental Validity. Behaviour Research and Therapy, 45, 1619-1628. http://dx.doi.org/10.1016/j.brat.2006.08.001

Taku, K., Arnie, C., Richard G. T., \& Lawrence, G. C. (2009). Intrusive versus Deliberate Rumination in Posttraumatic Growth across US and Japanese Samples. Anxiety, Stress and Coping, 22, 12-136. http://dx.doi.org/10.1080/10615800802317841

Taylor, R. (2005). Self-Ownership and the Limits of Libertarianism. Social Theory and Practice, 31, 465-482. http://dx.doi.org/10.5840/soctheorpract200531423

Uchida, Y., Kitayama, S., Mesquita, B., Reyes, J. A. S., \& Morling, B. (2008). Is Perceived Emotional Support Beneficial? Well-Being and Health in Independent and Interdependent Cultures. Personality and Social Psychology Bulletin, 34, 741-754. http://dx.doi.org/10.1177/0146167208315157

Uchida, Y., Norasakkunkit, V., \& Kitayama, S. (2004). Cultural Constructions of Happiness: Theory and Empirical Evidence. Journal of Happiness Studies, 5, 223-239. http://dx.doi.org/10.1007/s10902-004-8785-9

Uchida, Y., Townsend, S. S. M., Markus, H. R., \& Bergsieker, H. B. (2009). Emotions as within or between People? Cultural Variation in Lay Theories of Emotion Expression and Inference. Personality and Social Psychology Bulletin, 35, 1427-1439. http://dx.doi.org/10.1177/0146167209347322

Uyl, D. J. D., \& Rasmussen, D. B. (2003). Self-Ownership. The Good Society, 12, 50-57. http://dx.doi.org/10.1353/gso.2004.0019

Wang, J., \& Wang, X. (2012). Structural Equation Modeling: Applications Using Mplus. Hoboken, NJ: Wiley. http://dx.doi.org/10.1002/9781118356258

Weber, C. S., Thayer, J. F., Rudat, M., Perschel, F. H., Buchholz, K., \& Deter, H. C. (2007). Emotional Irritation before Mental Stress Is Associated with Enhanced Peripheral Norepinephrine. Cognition and Neurosciences, 48, 459-466. http://dx.doi.org/10.1111/j.1467-9450.2007.00612.x

Xiao, J. J., \& Li, H. F. (2011). Sustainable Consumption and Life Satisfaction. Social Indicators Research, 104, $323-329$. http://dx.doi.org/10.1007/s11205-010-9746-9

Ypi, L. (2011). Self-Ownership and the State: A Democratic Critique. Ratio, 24, 91-106. http://dx.doi.org/10.1111/j.1467-9329.2010.00485.x

Zebb, B. J. (1998). Worry versus Anxiety: Is There Really a Difference? Behavior Modification, 22, 45-61. http://dx.doi.org/10.1177/01454455980221003

Ziaian, T., Sawyer, J., Evans, N., \& Gillham, D. (2015). The Impact of Mindfulness Meditation on Academic Well-Being and Affective Teaching Practices. Creative Education, 6, 2174-2185. http://dx.doi.org/10.4236/ce.2015.620222

Zinbarg, R. E. (1998). Concordance and Synchrony in Measures of Anxiety and Panic Reconsidered: A Hierarchical Model of Anxiety and Panic. Behavior Therapy, 29, 301-323. http://dx.doi.org/10.1016/S0005-7894(98)80009-9 